\title{
Hippocampal functional organization: A microstructure of the place cell network encoding space
}

\author{
Constantine Pavlides $^{\mathrm{a}, *}$, Tomohiro Donishi ${ }^{\mathrm{a}, 1}$, Sidarta Ribeiro ${ }^{\mathrm{a}, 2}$, Claudio V. Mello ${ }^{\mathrm{a}, 3}$, \\ Wilfredo Blanco ${ }^{\mathrm{b}}$, Sonoko Ogawa ${ }^{\mathrm{a}, 4}$ \\ ${ }^{a}$ The Rockefeller University, New York, NY 10065, USA \\ ${ }^{\mathrm{b}}$ State University of Rio Grande do Norte, Natal, Brazil \& Brain Institute, Federal University of Rio Grande do Norte, Natal, Brazil
}

\section{A R T I C L E I N F O}

\section{Keywords:}

Hippocampus

Place cells

Spatial map

Cluster-type organization

Immediate early genes

Zif268

\begin{abstract}
A B S T R A C T
A clue to hippocampal function has been the discovery of place cells, leading to the 'spatial map' theory. Although the firing attributes of place cells are well documented, little is known about the organization of the spatial map. Unit recording studies, thus far, have reported a low coherence between neighboring cells and geometric space, leading to the prevalent view that the spatial map is not topographically organized. However, the number of simultaneously recorded units is severely limited, rendering construction of the spatial map nearly impossible. To visualize the functional organization of place cells, we used the activity-dependent immediateearly gene Zif268 in combination with behavioral, pharmacological and electrophysiological methods, in mice and rats exploring an environment. Here, we show that in animals confined to a small part of a maze, principal cells in the CA1/CA3 subfields of the dorsal hippocampus immunoreactive (IR) for Zif268 adhere to a 'clustertype' organization. Unit recordings confirmed that the Zif268 IR clusters correspond to active place cells, while blockade of $\mathrm{NMDA}_{\mathrm{R}}$ (which alters place fields) disrupted the Zif268 IR clusters. Contrary to the prevalent view that the spatial map consists of a non-topographic neural network, our results provide evidence for a 'clustertype' functional organization of hippocampal neurons encoding for space.
\end{abstract}

\section{Introduction}

Based on the discovery of 'place cells' (O'Keefe \& Dostrovsky, 1971), O'Keefe and Nadel (1978) proposed that the hippocampus functions as a 'cognitive' or 'spatial' map. Although the existence of place cells is unequivocal, the configuration of the spatial map remains a mystery. Both theoretical models (Dabaghian, Mémoli, Frank, \& Carlsson, 2012; Harris, 2005; Tsodyks, 1999) and empirical observations (Buzsáki, 2010; Harris, Csicsvari, Hirase, Dragoi, \& Buzsáki, 2003; Pastalkova, Itskov, Amarasingham, \& Buzsáki, 2008; Wills, Lever, Cacucci, Burgess, \& O'Keefe, 2005; Wilson \& McNaughton, 1993) suggest that space is represented by the synchronized activity of ensembles of cells. However, whether and how these may be topographically organized is not known. The majority of electrophysiological unit recording studies find a low coherence between geometric space and neighboring place cells (O'Keefe, Burgess, Donnett, Jeffery, \& Maguire, 1998). Thus, knowing the proximity of place cells to each other provides few clues as to what their place fields may be, and by extension, how the map may be constructed. Based on this evidence, the consensus view is that the spatial map consists of a widely distributed, non-topographically arranged neural network (McNaughton \& Morris, 1987; O'Keefe et al., 1998). Nonetheless, a few studies have suggested that a functional topographic organization of hippocampal cells may exist in animals performing either a spatial task or spatial exploration. Using multiunit recordings it was observed that place fields of neural ensembles (i.e., neighboring cells) were clustered (Deadwyler \& Hampson, 1999;

\footnotetext{
Abbreviations: ABC, avidin-biotin complex; CPP, (3-(2-carboxypiperazin-4-yl)-propyl-1-phosphonic acid); IEG, immediate early gene; IHC, immunohistochemistry;

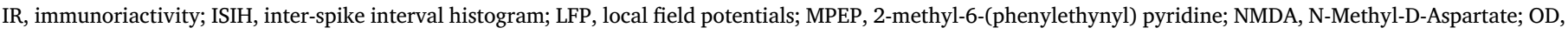
optical density; PB, phosphate buffer; PBS, phosphate buffer saline; SD, standard deviation

* Corresponding author.

E-mail address: pavlide@rockefeller.edu (C. Pavlides).

${ }^{1}$ Present address: Department of Physiology, Wakayama Medical University, Wakayama, Japan.

${ }^{2}$ Present address: Brain Institute, Federal University of Rio Grande do Norte, Natal, Brazil.

${ }^{3}$ Present address: Department of Behavioral Neuroscience, Oregon Health \& Science University, Portland, OR, USA.

${ }^{4}$ Present address: Laboratory of Behavioral Neuroendocrinology, University of Tsukuba, Tsukuba, Japan.
} 


\section{A}

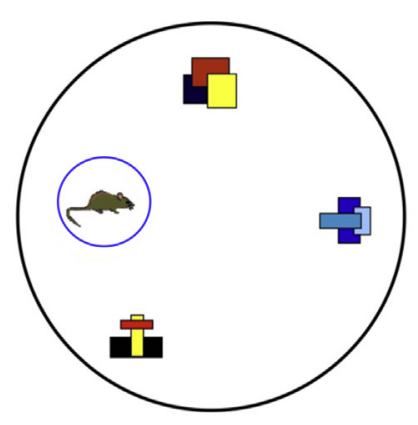

B
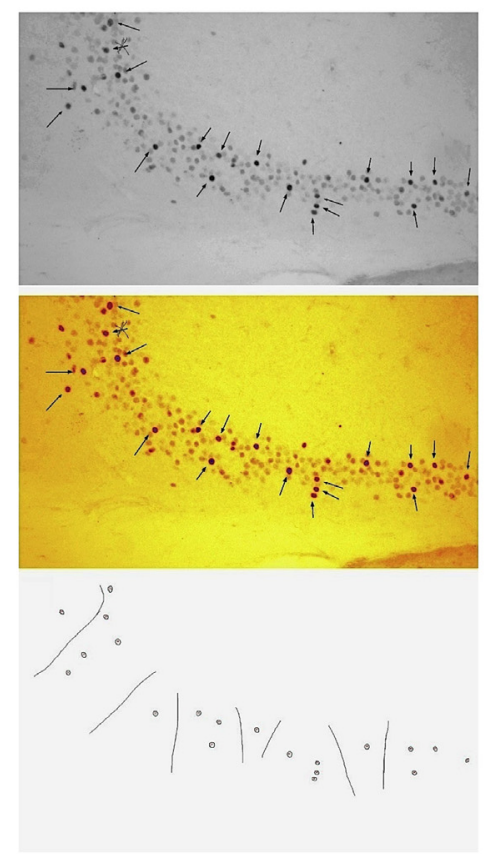

Fixed Location

C
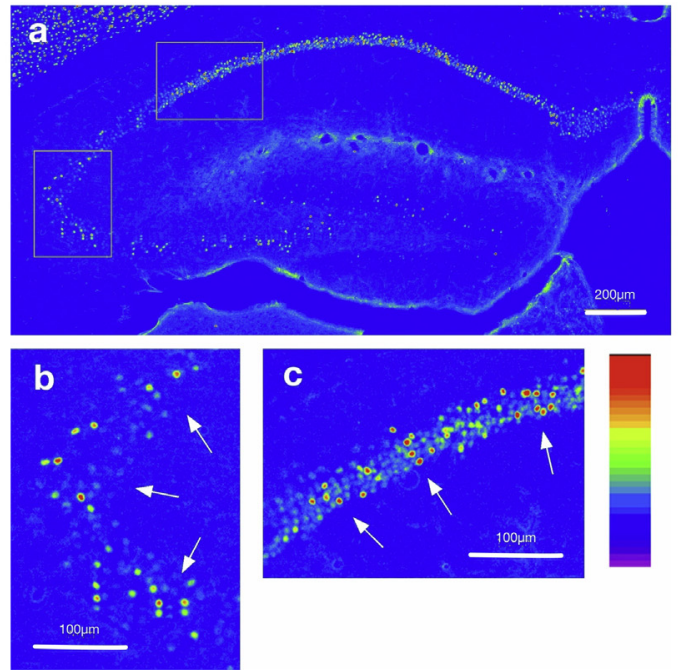

Free Exploration
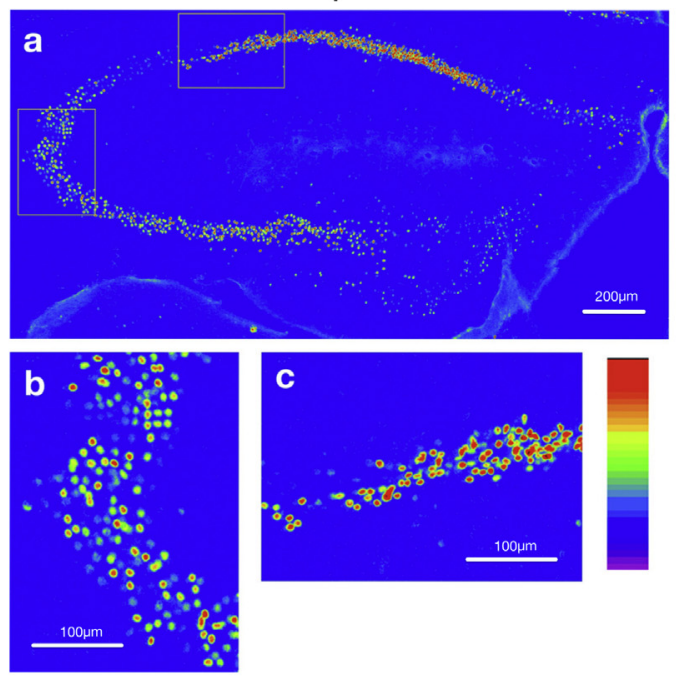

Non-Exposed Control
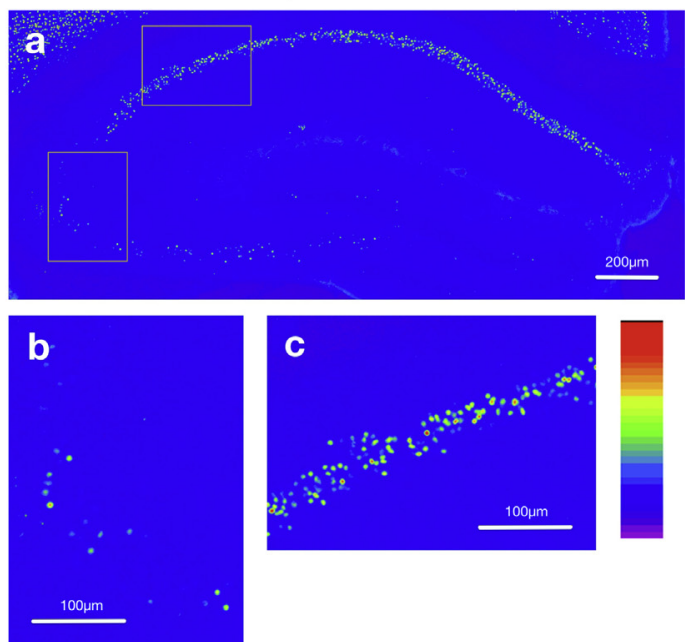

Fig. 1. Cluster-type functional organization in the dorsal hippocampus. (A) Schematic of circular maze. The maze contained three objects made of Lego building blocks. For the Fixed-Location group, mice were restricted to a small area by placing them inside a clear, cylindrical plexiglass tube. (B) Zif268 IR cell cluster analysis. Using NIH ImageJ, Zif268 IR cells were first thresholded (top), number-tagged and color transformed (middle). An average distance between IR cells was then calculated and a cluster was defined as cells falling within the mean +2 SD. Lines between cells (bottom) indicate cluster demarkations. (C) Representative Zif268 expression images. Lower case letters show: a, entire hippocampus; b and c, magnification of area indicated with square box in CA3 and CA1, respectively. The color scale represents gradient of optical density of stained cells (top-to-bottom - lowest-to-highest). For the Fixed-Location group (top, $\mathrm{n}=6$ ) there were clusters of a few IR cells (arrows), adjacent to non-Zif268 expressing cells. In contrast, in the Free-Exploration group (middle, $\mathrm{n}=6$ ), there were markedly more Zif268 IR cells which were evenly distributed. There were very few Zif268 IR cells in the NonExposed control group (bottom, $\mathrm{n}=6$ ).
Eichenbaum, Wiener, Shapiro, \& Cohen, 1989; Hampson, Byrd, Konstantopoulos, Bunn, \& Deadwyler, 1996). A similar clustering of CA1/CA3 pyramidal cell activity was observed for non-spatial (e.g., delayed matching/non-matching to sample) tasks, as well as non-spatial components of various tasks (Hampson et al., 1996; Hampson, Simeral,
\& Deadwyler, 1999). Still, a main obstacle in obtaining a better view of the functional neuronal organization of the spatial map is that the number of simultaneously recorded cells is small (even though recently it could range in the hundreds of cells), along with other technical limitations (to be discussed below). Construction of the spatial map 
would, therefore, require different or a combination of methods that would allow the simultaneous assessment of activity of the entire placecoding population.

An alternative way of identifying neuronal activity has been through the use of immediate-early genes (IEGs). IEGs, such as Arc, cfos, Homer 1a and Zif268, are activated rapidly and transiently by various stimuli and are coupled to cellular activity (Worley et al., 1991; for reviews, see Guzowski et al., 2005; Kawashima, Okuno, \& Bito, 2014). Previously, Zif268 and c-fos have been used successfully to show functional compartments within ocular dominance columns in the visual cortex (Takahata, Higo, Kaas, \& Yamamori, 2009). In the hippocampus, several studies have reported that a subpopulation of neurons express IEGs in response to exposure of an animal to a novel environment or a spatial task (Chawla et al., 2005; Guzowski, McNaughton, Barnes, \& Worley, 1999; Guzowski, Setlow, Wagner, \& McGaugh, 2001; Vann, Brown, Erichsen, \& Aggleton, 2000; Vazdarjanova, McNaughton, Barnes, Worley, \& Guzowski, 2002; for reviews, see Kubik, Miyashita, \& Guzowski, 2007; Miyashita, Kubik, Lewandowski, \& Guzowski, 2008). However, these studies have either not analyzed the distribution of IEG expressing cells or failed to observe a topographic organization (Redish et al., 2001).

Using Zif268 labelling in combination with behavioral, pharmacological, electrophysiological and computational methods, we now provide evidence for a cluster-type functional organization of hippocampal place cells to encode for space. We observed that in animals exposed to a restricted part of an environment, Zif268 IR cells formed clusters of a few active cells adjacent to non-active cells. Further, $\mathrm{NMDA}_{\mathrm{R}}$ blockade, which is known to disrupt the long-term stability of place cells (Kentros et al., 1998; for review see Nakazawa, McHugh, Wilson, \& Tonegawa, 2004) also disrupted the Zif268 IR cell clusters. Finally, we recorded within the Zif268 IR clusters and show that they correspond to active place cells. All together, the results suggest that the hippocampus conforms to a cluster-type functional organization to encode for space. We believe this to be a fundamental organizational principle for this structure.

\section{Methods}

\subsection{Subjects}

The experiments to determine topographic organization of Zif268 expression and effects of N-methyl-D-aspartate (NMDA) blockade on such expression were performed on male, C57BL/6J mice (Charles River Labs, Wilmington, MA, USA; 29.6-38.8 g, at time of testing). Mice were group housed and kept on a 12:12 h light:dark cycle, lights on at 08:00 h, with food and water available ad libitum. Two days prior to the experiment, the mice were single housed and kept in an isolation chamber. The experiments in which place cells were recorded were performed on male, Long-Evans rats (Charles River Labs; $360-540 \mathrm{~g}$, at time of testing). The rats were group housed, with food and water available ad libitum. After surgery for the implantation of electrodes, they were single housed. Following recovery from surgery, they were food restricted to $80 \%$ of their ad libitum weight, to enhance their exploratory behavior by searching for food pellets on the maze. All animals were treated in accordance with the National Institute of Health Guide for Care and Use of Laboratory Animals (NIH publication No. 8023, revised 1996) and approved by The Rockefeller University Animal Care and Use Committee. All efforts were made to minimize the number of animals used as well as their stress and suffering.

\subsection{Apparatus and behavioral testing}

In the experiments to determine functional organization, mice were tested on a circular maze (Fig. 1A). The maze was constructed from sheet metal that was looped to form a cylinder. The wall of the maze was uniformly white and was $120 \mathrm{~cm}$ in diameter and $40 \mathrm{~cm}$ high. The floor of the maze consisted of thick black paper while the ceiling was covered with a white semi-transparent paper that would allow even illumination to go through but prevented the animals from seeing outside cues. The animal's behavior was observed through a small pinhole on the top. Three different shaped objects (Lego building blocks; Billund, Denmark) were placed inside the maze in a triangular configuration.

To minimize background Zif268 expression (that may result from novelty or stress), animals were exposed to the test apparatus on two consecutive days. To further suppress Zif268 expression (that may result from various stimuli), they were confined to an isolation chamber for $48 \mathrm{~h}$, immediately prior to the experiments. The isolation chamber was soundproofed and totally dark. Repeated exposure to the test apparatus would also activate place cells and establish a spatial map. (Based on electrophysiological studies, place fields form rather quickly - within a few minutes of an animal entering a new place - while repeated exposure to the same place stabilizes place fields (Frank, Stanley, \& Brown, 2004; Hill, 1978; Wilson \& McNaughton, 1993). Once established, place fields are relatively stable - that is, if an animal is brought back to the same environment days to weeks later, the same subset of place cells become engaged (Muller, Kubie, \& Ranck, 1987; Thompson \& Best, 1990).)

On the day of the experiment, the animals were exposed to the maze for 15 min with lights on. There were three groups of animals: (1) FixedLocation - animals were placed in a transparent Plexiglas cylinder $(12 \mathrm{~cm}$ diameter, $18 \mathrm{~cm}$ high), located on one side of the maze. There was sufficient space for the animals to move around and not be completely confined. The view of the rest of the maze and the objects within the maze was unobstructed; (2) Free-Exploration - animals were placed on the center of the maze and allowed to free explore for $15 \mathrm{~min}$. Following exposure to the maze, the animals were returned to their home cage and were placed in isolation for $2 \mathrm{~h}$, following which they were deeply anesthetized (Nembutal), perfused, and their brains processed for Zif268 immunohistochemistry (IHC); (3) A group of NonExposed (home cage) controls were also included. These animals were kept in their home cages at the center of the maze for a similar amount of time with the lights turned off (complete darkness). At the end of this period they were placed in isolation for $2 \mathrm{~h}$ following which they were deeply anesthetized, perfused and their brains processed for Zif268 IHC.

In the experiments to test effects of N-methyl-D-aspartate receptor $\left(\mathrm{NMDA}_{\mathrm{R}}\right)$ antagonists on functional organization, mice were tested on an 8 -arm maze (Fig. 4A). The arms of the maze were $40 \times 8 \mathrm{~cm}$, and were enclosed with clear plexiglass. The maze was located in a black painted room approximately $3 \mathrm{~m}^{2}$. A number of visual cues were placed on the walls and on the side of the arms. The animals were exposed to the maze for two days prior to the experiment. They were then placed in an isolation chamber for $48 \mathrm{~h}$. On the day of the experiment, the animals were injected either with the $\mathrm{NMDA}_{\mathrm{R}}$ antagonist CPP $(10 \mathrm{mg} / \mathrm{kg}$, IP, Sigma-Aldrich, St. Louis, MO, USA) or the vehicle (saline). They were then placed inside a stainless steel cylinder $(15 \mathrm{~cm}$ in diameter, $25 \mathrm{~cm}$ high) located in the center of the maze, with lights turned off, for $1 \mathrm{~h}$. Following this, they were exposed either to one of the arms (FixedLocation group) or allowed to explore the entire maze (Free-Exploration group) for $15 \mathrm{~min}$. They where then placed back in the stainless steel cylinder for $2 \mathrm{~h}$ (lights off) following which they were anesthetized (Nembutal), perfused and their brains processed for Zif268 IHC.

To determine effects of locomotion on Zif268 expression, one group of mice $(n=3)$ was tested on a running wheel. The running wheel was placed inside the circular maze, with no visual cues. The animals were placed on the wheel and closed in with a door, to promote continuous locomotion. The running wheel had an automatic counter to record activity levels. The animals were acclimated to the running wheel on two consecutive days, followed by isolation for $48 \mathrm{~h}$. On the day of the experiment, they were placed on the running wheel for $15 \mathrm{~min}$ and were then returned to their home cage for $2 \mathrm{~h}$ following which they 
were anesthetized (Nembutal), perfused and processed for Zif268 IHC. All of these procedures were performed in the dark (under red light).

In the experiments in which unit activity was recorded, rats were tested either on a 'plus' (Fig. 5B) or an 8-arm maze (Fig. 6C). The maze was located in a black painted room approximately $3 \mathrm{~m}^{2}$, with a number of visual cues attached to the wall. Following recovery from surgery, the animals were tethered to electrophysiological equipment and unit recordings were performed, while they were foraging for food. Once successful recordings that met the experimental criteria (i.e., at least 2 cells from different electrodes and non-overlapping place fields) were achieved, the animals were placed in an isolation chamber for $48 \mathrm{~h}$ prior to the experiment. On the day of the experiment, they were confined to the place field of a chosen cell either by placing a Plexiglass barrier on the arm or with a cylindrical wire mesh that was placed over the place field. Neither of these methods obstructed the animal's view of the environment. Recordings were performed during this exposure to assess the unit's activity. In all cases, the behavior was either video recorded or observed on-line and carefully documented.

\subsection{Anatomy}

\subsubsection{Immunohistochemistry}

IHC methods were similar to those described previously (Mello \& Ribeiro, 1998). Briefly, animals were deeply anesthetized with Nembutal $(100 \mathrm{mg} / \mathrm{kg})$ and perfused sequentially with phosphate-buffered saline (PBS; $\mathrm{pH} 7.4$ ), and $4 \%$ paraformaldehyde in $0.1 \mathrm{M}$ phosphate buffer (PB; pH 7.4). The brains were removed, washed overnight at $4{ }^{\circ} \mathrm{C}$ in $0.1 \mathrm{MPB}$ under agitation, incubated in $20 \%$ sucrose in $0.1 \mathrm{M} \mathrm{PB}$, frozen and stored at $-80^{\circ} \mathrm{C}$. $30 \mu \mathrm{m}$ sections were cut on a freezing microtome and stored in PBS at $4^{\circ} \mathrm{C}$. Free-floating sections were then incubated sequentially as follows: (1) $20 \mathrm{~min}$ at room temperature in avidin blocking solution followed by $20 \mathrm{~min}$ at room temperature in biotin blocking solution in $0.1 \mathrm{M}$ PBS, at the dilution recommended by the manufacturer (Vector blocking kit; Vector Laboratories, Burlingame, CA, USA); (2) $60 \mathrm{~min}$ at room temperature in blocking solution ( $3 \%$ skim milk and $0.3 \%$ Triton X-100 in $0.1 \mathrm{M}$ PBS); (3) $24 \mathrm{~h}$ at $4{ }^{\circ} \mathrm{C}$ in blocking solution containing a rabbit anti-egr-1 antiserum $(0.01 \mu \mathrm{g} / \mathrm{ml}$; C-19, Santa Cruz Biotechnology, Santa Cruz, CA, USA) raised against the carboxy-terminus of mouse egr- 1 ; (4) $2 \mathrm{~h}$ at room temperature in blocking solution containing biotinylated goat anti-rabbit IgG (1:400, Vector Laboratories); and (5) $1 \mathrm{~h}$ at room temperature in avidin-biotin complex $(\mathrm{ABC})$ reagent at the dilution recommended by the manufacturer (Vector Laboratories). Each of the steps above were followed by three washes (10 min each) in 0.1 M PBS (pH 7.4), except between steps 2 and 3 . The sections were then developed by incubation in $0.03 \%$ diaminobenzidine, $0.15 \%$ nickel-ammonium sulfate, and $0.001 \% \mathrm{H}_{2} \mathrm{O}_{2}$ in PBS followed by rinsing in PBS. They were mounted on gelatin coated microscope slides, air dried, dehydrated, and cover-slipped with DPX (Sigma-Aldrich). To assess the specificity of our detection system, IHC controls were run as described above but omitting incubations with either the primary or secondary antisera. The pre-absorption control was performed by incubating the anti-Zif268 antiserum at the working dilution with a ten-fold excess (by weight) of the corresponding preabsorption peptide, essentially as recommended by the manufacturer (Santa Cruz Biotechnology). Sections from different treatment groups were processed for IHC at the same time.

\subsubsection{Image analysis and distribution of Zif268 IR cells}

All image and cellular distribution analysis was done blind with regards to experimental/control groups. Two brain sections at approximately the same stereotaxic coordinates, from each group of animals, were scanned on a light microscope (Olympus BX60, Tokyo, Japan) at 10X magnification and the entire hippocampal area in each section was reconstructed by means of a stereology setup (Intelligent Imaging Innovations, SlideBook 4.1, Denver CO, USA). Using NIH ImageJ software, Zif268 IR cells were then selected by first taking an average optical density (OD) for a large number of cells ( $>100)$ within a specific hippocampal area (i.e., CA1, CA3, dentate gyrus (DG)) and operationally defining Zif268 IR positive cells as those exceeding 2 standard deviations (SDs) above the mean OD. Using this threshold, all Zif268 IR cells were number-tagged. Since Zif268 IR cells differed in density across different fields (i.e., CA1, CA3, DG), we performed a separate analysis for each field. Besides optical density, the average diameter $( \pm$ SD) of the Zif268 IR cells was also calculated. This measure was used to avoid miscounting very closely located cells. Cells exceeding the mean +2 SDs diameter were counted as two (or more) cells. For quantification of cell clusters in the CA1 hippocampal field, the total number of cells per $50 \mu \mathrm{m}$ was calculated and plotted over approximately a $2.5 \mathrm{~mm}$ area, extending from the most proximal to the most distal part of CA1. A similar analysis was performed in the CA3 field, spanning between fields CA4 and CA2. The formation of clusters was determined by first calculating the average distance between each Zif268 IR cell and its closest neighbor within an area (e.g., CA1, CA3). Since the compactness (i.e., distances between cells) differed between the CA1 and CA3 fields (data not shown), a separate analysis was performed for the two fields. A cluster was then defined as two or more cells located within the average distance +2 SDs. Cells falling outside this distance were considered as belonging to a different cluster (or were part of a non-cluster, i.e., single cells; Fig. 1B). For all measures, an average was calculated for all animals and used for the comparisons across groups. Differences in the number of clusters, cells within a cluster and distances between clusters, were analyzed with 2 -tailed $\mathrm{t}$ tests with significance set to $p<0.05$.

In order to further establish whether the Zif268 IR cells adhered to a non-random distribution, we used NIH ImageJ and customized MatLab software to simulate random placements (x-y coordinates) of the nuclear labelling within each reconstructed hippocampus. For each animal in the Fixed-Location ( $n=4$, randomly selected from a total of 6 animals) and CPP injected ( $n=4)$ groups, a separate mask of all the Zif268 IR cells was made for the CA1 and CA3 fields, by running 300 random iterations to provide the simulated $\mathrm{x}$-y coordinates of each cell. A circular nuclear shape area was calculated using the average diameter of the Zif268 IR cells. The hippocampal boundary was maintained and the simulated labeled nuclei were randomly placed within it; spatial overlaps were resolved by randomly replacing the incoming cell nucleus. Differences between real and random distributions of clusters were analyzed using a two-sample Kolmogorov-Smirnov test, significance set to $\mathrm{p}<0.05$.

\subsection{Electrophysiology}

\subsubsection{Electrodes and surgery: Single electrodes}

The electrodes consisted of tungsten rod, etched to a fine tip. These were insulated with Epoxylite (The Epoxylite Corp., Irvine, CA, USA) except for $10-15 \mu \mathrm{m}$ off the tip. The electrodes were 'bubbled' (1 mA positive current, $<1 \mathrm{~s}$ ) to clear the tip and produce impedances of $\sim 0.2-0.7 \mathrm{M} \Omega$ (prior to implantation; measured at $1 \mathrm{kHz}$ ). This provided two advantages: (1) due to their sharp tips they caused minimum damage to brain tissue; (2) due to the relatively higher impedances (than tetrodes) they allowed the recording from a few close-by cells, thus, allowing the identification of the recording site in relation to the Zif268 IR clusters. The electrodes were mounted on a custom-built microdrive assembly that was both moveable and sufficiently compact to allow bilateral implants (Fig. 6A). By rotating a screw on the assembly, the electrodes advanced in small (10-20 $\mu \mathrm{m})$ increments. Each assembly could be moved independently so that single unit recordings were optimized for each hemisphere.

\subsubsection{Multi-electrode arrays}

Recordings from different clusters of cells were also accomplished with custom-built multi-electrode arrays. The electrodes consisted of stainless steel insect pins (Fine Science Tools, Foster City, CA, USA), 
which were insulated with Epoxylite. The insulation was scraped off the tip $(10-15 \mu \mathrm{m})$ and 'bubbled' ( $1 \mathrm{~mA}$ positive current, $<1 \mathrm{~s}$ ) to produce impedances $\sim 0.2-0.7 \mathrm{M} \Omega$ (prior to implantation; measured at $1 \mathrm{kHz}$ ). The array contained 6-8 electrodes, arranged in two rows with a spacing between each electrode of $\sim 200 \mu \mathrm{m}$. The electrode array was mounted to a custom-built microdrive (Fig. 5A). The microdrive consisted of a 10 pin connector (Omnetics, Corp, Minneapolis, MN, USA) which was set in a dental cement block. The block also consisted of two screws at the bottom of which were posts made of cement. The posts were attached to the animal's head, which was anchored to skull screws. By rotating the two screws the assembly advanced at small $(10-20 \mu \mathrm{m})$ increments.

\subsubsection{Surgery}

Rats were deeply anesthetized with sodium pentobarbital $(50 \mathrm{mg}$ / $\mathrm{kg}$, i.p., with supplemental doses as needed). During surgery, the depth of the anesthesia was monitored on a regular basis by toe pinch reflex, respiratory and heart rate. Further, the animal's temperature was monitored and controlled with a homeothermic temperature control unit (Harvard Apparatus, Holliston, MA, USA). After deep anesthesia was reached, the animal was mounted on a stereotaxic frame (Kopf Instruments, Tujunga, CA, USA). The skin over the skull was incised and retracted. Four anchoring screws (for holding the electrode assembly) were screwed into the skull. One of the screws also served for grounding the animal to the equipment. Depending on whether unilateral or bilateral electrode implants were performed, one burr hole was drilled on the left hemisphere or bilaterally, for the insertion of the electrode assemblies. The electrodes were aimed at the dorsal hippocampus, either the CA1 or CA3 cell body layers (parallel to the mid-sagittal suture), at the following coordinates: A-P, bregma - $3.1 \mathrm{~mm}$; M-L, midsagittal suture $\pm 3.2 \mathrm{~mm}$; D-V, $-2.5 \mathrm{~mm}$ from skull surface (slightly adjusted for CA3). During the implantation, recordings were performed and the CA1/CA3 pyramidal cell layer was localized. The electrodes were then retracted $\sim 200 \mu \mathrm{m}$ above the cell body layer and the assemblies were cemented to the skull. At the completion of surgery, a triple antibiotic ointment was applied to the wound and the animals were injected (I.P.) with Penicillin (75,000 U) to prevent infections. The animals were placed in their home cage heated with a lamp to maintain temperature and were monitored till recovering from anesthesia. For the reduction of pain, liquid Ibuprofen $(100 \mathrm{mg}$ ) was added to the drinking water. The animals were allowed $7-10 \mathrm{~d}$ recovery before being used in an experiment.

\subsubsection{Unit recordings and discrimination}

Following the recovery period, recordings were initiated while the animals were freely behaving either on a 'plus' or an 8-arm maze. The electrodes were advanced slowly ( $\sim 40 \mu \mathrm{m} / \mathrm{d}$ at $20 \mu \mathrm{m}$ increments) to the pyramidal cell layer searching for units. Physiological recordings (including unit activity and local field potentials; LFPs) were made either with NB-MIO-16X, A/D converters and custom built software LabVIEW (National Instruments, Austin, TX, USA) or a Plexon system (Plexon, Inc., Dallas, TX, USA). For unit recordings, the gain was set at $10 \mathrm{~K}$ and the filters were set at $300 \mathrm{~Hz}-10 \mathrm{KHz}$. The signals were digitized at $20 \mathrm{KHz} / \mathrm{channel}$. For LFPs the filters were set at $3-300 \mathrm{~Hz}$. Recordings were stored on a computer hard drive for further off-line analysis. Once units were encountered, the recordings were optimized and each unit was discriminated and mapped for place fields. The objective was to identify two or more units with distinct, non-overlapping place fields recorded from different electrodes. Once this was accomplished, the animals were sequestered in an isolation chamber for $48 \mathrm{~h}$. On the day of the experiment, the animals were exposed for $15 \mathrm{~min}$ to the place field of one unit (by placing him inside a cylindrical wire mesh or confining him with clear plexiglas barriers), while restricting him from entering the place field of the second unit (Fig. 5B). Continuous recordings confirmed that the barriers did not alter the cell's place fields, as could occur with placement of opaque barriers (Muller \&
Kubie, 1987).

Unit discrimination and place maps were performed both on- and off-line. The on-line discrimination and place field map construction was essential to ensure that the unit being exposed displayed high firing rates, while the unit prevented from entering its place field had low firing rates. In off-line analysis, all units (with a signal-to-noise ratio of 2:1 or better) were discriminated and place field activity was again determined and mapped in 2-D place coordinates. Units were classified either as "complex spike" cells or "theta" cells and their firing repertoires were carefully documented. (Theta cells were excluded from further analysis.) Place fields were constructed from pixel firing rates, according to the algorithm created by Muller et al. (1987).

\subsubsection{Electrode localization}

Electrode localization was performed on the brain sections using light microscopy, along with stereotaxic measurements, at the time of electrode implantation, and subsequent electrode advances in search of place cells. The location of the electrode tip at its final recording position in stratum pyramidale was identified by reconstructing the trajectory of the electrode tract, which was clearly visible, given the relatively large diameter of the electrode shaft $(250 \mathrm{~mm})$, the chronic nature of the implant, and the fact that the brains were perfused prior to electrode removal. Furthermore, the hippocampal pyramidal layers are relatively narrow (CA1: approx. $50 \mu \mathrm{m}$; CA3 75-100 $\mu \mathrm{m}$ ) and the first encounter of pyramidal cells to the final destination was recorded. Thus, the location of the electrode tip, relative to Zif268 IR cells, could be estimated with a high degree of precision.

\subsubsection{Video recordings}

Besides, the physiological recordings, the Plexon system allowed for simultaneous video recordings of the animal's behavior. The video tracking system consisted of a CCD camera (Sony, ImagingSource, DFK21F04, Tokyo, Japan; placed on top of the maze), a dedicated computer that digitized and time-stamped location coordinates (which were then matched with unit firing) and software (Plexon, CinePlex) which coordinated video recordings, produced place maps from place location and unit firing, etc. The tracking of the animal's location was accomplished by having two LED's on the head stage which connected to the implant on the animal's head. The LEDs allowed both for location information as well as the animal's directionality.

\section{Results}

\subsection{Distribution of Zif268 IR cells}

In the Fixed-Location group $(n=6)$, Zif268 expressing cells were sparse but concentrated in clusters of a few active cells interspersed with non-active cells. The clusters were seen throughout the dorsal CA1 and CA3 fields (Fig. 1C, top panel). The average number of detected Zif268 IR clusters spanning the CA1 field were $7.8 \pm 0.9$ (Mean \pm SEM), while the number of cells/cluster were $4.6 \pm 0.5$ cells. In the CA3 field, the number of detected Zif268 IR clusters was $2.5 \pm 0.5$, while the number of cells per cluster was $3.8 \pm 0.7$. The average intercluster distance for the CA1 field was $137.6 \pm 36.6 \mu \mathrm{m}$, while in the CA3 field it was $200.1 \pm 34.2 \mu \mathrm{m}$. In marked contrast, in the FreeExploration group $(\mathrm{n}=6)$, there were markedly more Zif268 expressing cells than in the Fixed-Location group and they were evenly distributed throughout the CA1/CA3 fields (Fig. 1C, middle panel). In Non-Exposed (control, $\mathrm{n}=6$ ) animals, there were a lot fewer Zif268-expressing cells, than the exposed groups, and no clustering of Zif268-expressing cells was evident (Fig. 1C, bottom panel). The distribution of Zif268 IR cells in the CA1 field across the different experimental groups is presented in Fig. 2. Discounting single cells, the clusters become evident for the Fixed-Location group (Fig. 2a). The distance between clusters was approximately $200 \mu \mathrm{m}$. The average Zif268 IR cells in the Free-Exploration group was more evenly distributed (Fig. 2B; see also Table 1). 
A
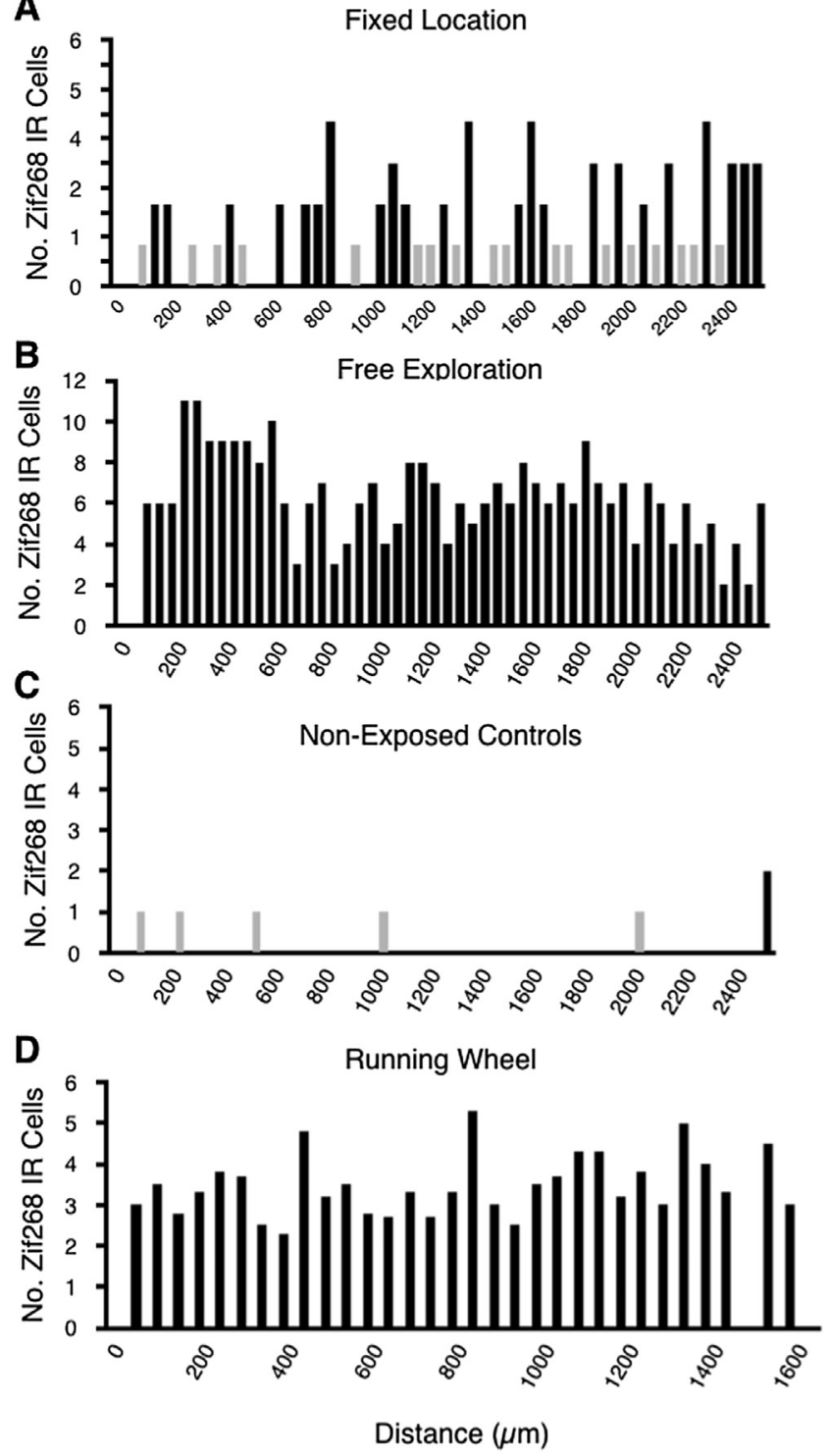

Fig. 2. Average distribution of Zif268 IR cells in the CA1 field of the dorsal hippocampus. Zif268 IR cells were quantified in $50 \mu \mathrm{m}$ intervals starting most proximal and extending approximately $2.5 \mathrm{~mm}$ most distal to CA3. Clear clusters become evident for the Fixed-Location group ( $\mathrm{A} ; \mathrm{n}=6$ ), while for the FreeExploration group ( $\mathrm{B} ; \mathrm{n}=6$ ) there were markedly more Zif268 IR cells which were also more evenly distributed. There were very few Zif268 IR clusters for the Non-Exposed group ( $\mathrm{C} ; \mathrm{n}=6$ ). The number of Zif268 expressing cells of the Running-Wheel animals ( $\mathrm{D} ; \mathrm{n}=4$ ) was approximately $1 / 4$ (Running-Wheel: $1.56 \pm 0.16$ vs Free-Exploration: $6.24 \pm 0.27$; Mean \pm SEM, p < 0.0001), compared to the Free-Exploration group, even though the locomotor activity was comparable (if not higher). Further, the Zif268 IR cells did not form clusters in the Running-Wheel group, as seen in the Fixed-Location group. Please note that single cells are displayed in gray.
The larger number of Zif268 IR cells in the Free-Exploration group could not be entirely accounted for by the higher locomotor activity, since allowing animals to free-run (for a similar amount of time) on a running wheel did not activate a comparable number of Zif268 cells as in the Free-Exploration group (Fig. 2D). In comparison to the Free-Exploration group (Fig. 2B), the number of Zif268 expressing cells in the CA1 field of the Running-Wheel animals $(n=4)$ was approximately $1 / 4$ (Free-Exploration: $6.24 \pm 0.27$ vs Running-Wheel: $1.56 \pm 0.16$, Mean \pm SEM; $\left.\mathrm{t}_{(10)}=7.14, \mathrm{p}<0.0001\right)$, even though the locomotor activity was higher (continuous running vs exploration) for the Running-Wheel group. Further, the Zif268 IR cells did not form clusters, as seen in the Fixed-Location group (Fig. 1C).

Unlike the cluster-type organization in the CA1/CA3 fields, we observed relatively fewer Zif268 IR cells in the ventral hippocampus and there was no evidence of clustering (Fig. 3). Similarly, we observed very few Zif268 expressing cells in the DG, especially in the Fixed-Location (Fig. 1C, top panel) and Control groups (Fig. 1C, bottom panel). For the Free-Exploration group some of the granule cells were Zif268 IR positive, albeit at lower expression levels than pyramidal cells (Fig. 1C, middle panel).

\subsection{Effects of $N M D A_{R}$ blockade on Zif268 IR cell distribution}

CPP administration produced a significant, although subtle, disruption of the Zif268 clusters, in the Fixed-Location group. In the CA1, the average number of clusters (in the entire field) was lower in the CPP $(\mathrm{n}=4)$ than in the vehicle-injected $(\mathrm{n}=4)$ control group $(5.7 \pm 0.6$ vs $\left.8.2 \pm 0.8 ; \mathrm{t}_{(17)}=2.52, \mathrm{p}<0.02\right)$. The average number of cells/ cluster, however, was not significantly different (CPP $5.3 \pm 0.5$ vs vehicle-injected controls $4.4 \pm 0.4, \mathrm{p}>0.05$; Fig. 4, middle panel). A significant difference was also observed in the distance between clusters (CPP, $56.9 \pm 4.0 \mu \mathrm{m}$ vs vehicle-injected Control, $116.5 \pm 30.2 \mu \mathrm{m}$; $\left.\mathrm{t}_{(16)}=2.2, \mathrm{p}<0.04\right)$, which would indicate less compactness of the clusters in the CPP group (i.e., cells within the cluster were more widely distributed). In the CA3 field of the CPP-injected animals, there were fewer clusters which approached but were not significantly different from the vehicle-injected control group (CPP, $1.5 \pm 0.3$ vs vehicle-injected controls, $2.6 \pm 0.5 ; \mathrm{p}=0.08$ ). Also, the number of cells/cluster did not differ significantly for the CA3 field (CPP, $3.8 \pm 0.6$ vs vehicleinjected controls, $3.4 \pm 0.9 ; \mathrm{p}>0.05$ ). Further, the distance between clusters in the CA3 field did not differ significantly between the CPP and vehicle-injected control group $(111.9 \pm 16.5 \mu \mathrm{m} \quad$ vs $181.1 \pm 30.4 \mu \mathrm{m} ; \mathrm{p}>0.05)$. Interestingly, CPP also dramatically reduced Zif268 expression in the Free-Exploration group (Fig. 4, bottom panel), compared to non-injected animals exposed to a complex environment (Fig. 1C, top panel).

To determine whether the Zif268 IR clustering we observed could have resulted randomly, we performed two-sample KolmogorovSmirnov tests to compare the closest neighbor distributions between real and randomized cell samples. (Table 2 shows the corresponding $\mathrm{p}$ values of the comparisons between distributions.) For the CA1 hippocampal field of the Fixed-Location group, the real samples were significantly different from the randomized samples in $3 / 4$ animals tested ( $\mathrm{p}<0.05$, bold values in Table 2). In contrast, for the CPP injected group, the distribution of the real sample was different than the randomized sample in 2 out of 4 animals. For the CA3 hippocampal field,

Table 1

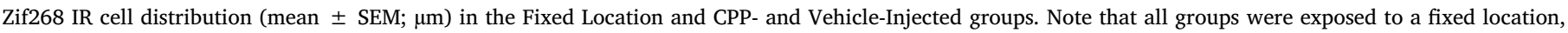
although location differed between the injected and non-injected groups.

\begin{tabular}{|c|c|c|c|c|c|c|c|c|c|}
\hline \multirow[b]{2}{*}{ Hipp. Field } & \multicolumn{3}{|c|}{ Fixed-Location } & \multicolumn{3}{|l|}{ CPP-Injected } & \multicolumn{3}{|c|}{ Vehicle-Injected } \\
\hline & No. Clusters & Cells/Cluster & Dist. Betw Clust. & No. Clusters & Cells/Cluster & Dist. Betw. Clust. & No. Clusters & Cells/Cluster & Dist. Betw. Clust. \\
\hline CA1 & $7.8 \pm 0.9$ & $4.6 \pm 0.5$ & $137.6 \pm 36.6$ & $5.7 \pm 0.6$ & $5.3 \pm 0.5$ & $56.9 \pm 4.0$ & $8.2 \pm 0.8$ & $4.4 \pm 0.4$ & $116.5 \pm 30.2$ \\
\hline CA3 & $2.5 \pm 0.5$ & $3.8 \pm 0.7$ & $200.1 \pm 34.2$ & $1.5 \pm 0.3$ & $3.8 \pm 0.6$ & $111.9 \pm 16.5$ & $2.6 \pm 0.5$ & $3.4 \pm 0.9$ & $181.1 \pm 30.4$ \\
\hline
\end{tabular}



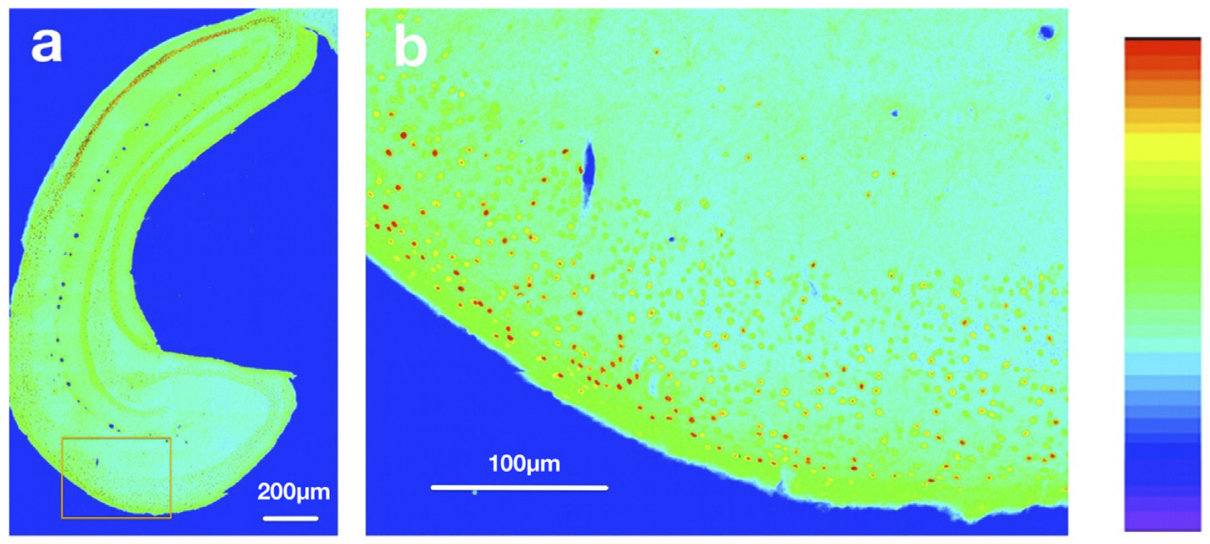

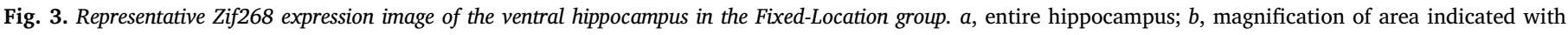
square box in $a$. In the ventral hippocampus, there were fewer Zif268 IR cells, and they were more diffusely scattered, compared to the dorsal hippocampus.

the distribution of real samples differed from randomized samples in 3 out of 4 animals in the Fixed-Location group while in the CPP injected group, the distributions differed significantly in only 1 out of 4 animals, indicating that $\mathrm{NMDA}_{\mathrm{R}}$ blockade disrupted the spatial-induced clusters.

\subsection{Recordings within Zif268 clusters}

In order to determine whether the Zif268 IR cell clusters observed in the Fixed-Location group correspond with the activity of place cells, we performed unit recordings in freely behaving animals. For a number of reasons (e.g., brain size; previous literature), these experiments were performed in rats. In preliminary studies, we also observed a clustertype organization of Zif268 IR cells, in rats exposed to a fixed location (data not shown). Successful recordings of two cells, located in different electrodes and with non-overlapping place fields were performed in three animals.

Representative recordings in the CA3 field are shown in Fig. 5. Using a multi-electrode array, recordings were made from 2 cells in the dorsal CA3 pyramidal cell layer, using two different electrodes. Unit 1 (sig 005, Fig. 5C, top) had a place field on the lower right arm. Unit 2 (sig007, Fig. 5C, bottom), had two circumscribed although disjointed place fields on the upper left arm (close to the center) and on the lower right arm. On the day of the experiment, the animal was placed within a wire mesh enclosure centered over one of Unit 2 place fields (Fig. 5C, bottom right) for $15 \mathrm{~min}$, while restricting it from the place field of Unit 1. During exposure to the place field, Unit 2 fired at high rates within its place field, while Unit 1 showed very low, background activity. Zif268 expression is shown in Fig. 5D, along with placement of the two electrodes. The tip of the electrode from which Unit 2 was recorded was localized within a Zif268 IR cluster (bottom; arrow) while the tip of the electrode from which Unit 1 was recorded was localized outside Zif268 IR cells (top; arrow).

Similar recordings were performed in the CA1 field (Fig. 5E). In this example, two different cells were recorded simultaneously. Unit 1 (sig003) had a place field on the start of the lower left arm while Unit 2 (sig005) had a place field on the right side of the center platform. On the day of the experiment, the animal was exposed to the place field of Unit 2, while being prevented from entering the place field of Unit 1. During the exposure, Unit 2 fired at high rates while Unit 1 was practically silent. Zif268 expression is shown in Fig. 5F. Histological examination revealed that the tip of the electrode for Unit 2 was localized within a Zif268 IR cell cluster (left arrow) while the tip of the electrode used to record Unit 1 was localized outside Zif268 IR cells.

In a third experiment, recordings were performed bilaterally in the CA1 field using single sharp electrodes (Fig. 6). Animals were tested in an 8-arm maze. Two units were recorded simultaneously. Unit 1 had a discrete place field in the start of arm 7 while Unit 2 displayed enhanced firing in arms 3,4 and 5. During the experiment, the animal was restricted to arm 7, for $7 \mathrm{~min}$. Zif268 expression is shown in Fig. 6D. As in the previous two experiments, the electrode tip from Unit 1 was localized within a Zif268 IR cluster while the tip from which Unit 2 was recorded was localized outside Zif268 IR cells. Taken together, these results show that the Zif268 IR clusters represent active place cells.

\section{Discussion}

The hypothesis put forward by O'Keefe and Nadel (1978) that the hippocampus functions as a 'cognitive' or 'spatial' map is supported not only by the discovery of place cells, but also by numerous behavioral/ lesion studies in animals (for reviews see, Eichenbaum, Dudchenko, Wood, Shapiro, \& Tanila, 1999; Poucet, Save, \& Lenck-Santini, 2000) and brain imaging studies in humans (Maguire et al., 1998). With regards to the functional neuronal organization that comprises the 'spatial map', the dogma, thus far, has been that it is essentially random. This is based on unit recordings - the majority of which show no topographic organization of place cells - along with the fact that both the extrinsic and intrinsic projections are extensive and make en passant-type contact with numerous cells, suggesting a random-type functional organization. Using a combination of molecular, behavioral, pharmacological and recording methods and by restricting the spatial exposure of animals to a small part of an environment, we show here that hippocampal principal cells in the dorsal CA1/CA3 fields form clusters of a few active cells adjacent to non-active cells, thus providing clear evidence of a topographic functional arrangement in the hippocampus. This is reminiscent of the cluster-type organization that has been observed in sensory neocortex (Hubel \& Wiesel, 1965; Mountcastle, 1997) and would best conform to the lamellar-type hippocampal organization proposed by Andersen, et al. (Andersen, Bliss, \& Skrede, 1971). Although the lamellar hypothesis fell into disfavor for some time, based on anatomical evidence showing divergent projections along the hippocampal longitudinal axis, its validity has recently been revisited (Sloviter \& Lømo, 2012). Thus far, our analysis concentrated on a narrow portion of the dorsal hippocampus and the clusters we observed spanned the proximal-distal extent of the CA1 and CA3 fields. On the other hand, the lamellar organization proposed by Anderson and colleagues referred to the septal-temporal axis - although speculative, we propose that a cluster-type organization will also be true in this axis.

Interestingly, the clusters became evident only when animals were exposed to a small part of the environment, while in animals allowed to explore the entire maze, there were markedly more Zif268 expressing cells and they were evenly distributed throughout the CA1/CA3 fields. The most parsimonious explanation is that by exploring a larger part of the environment more place cells became engaged. The increase in the 


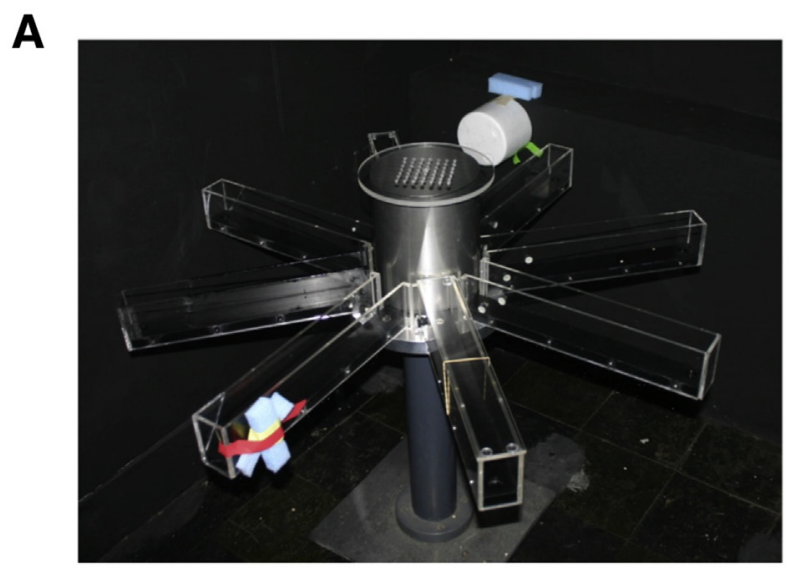

B
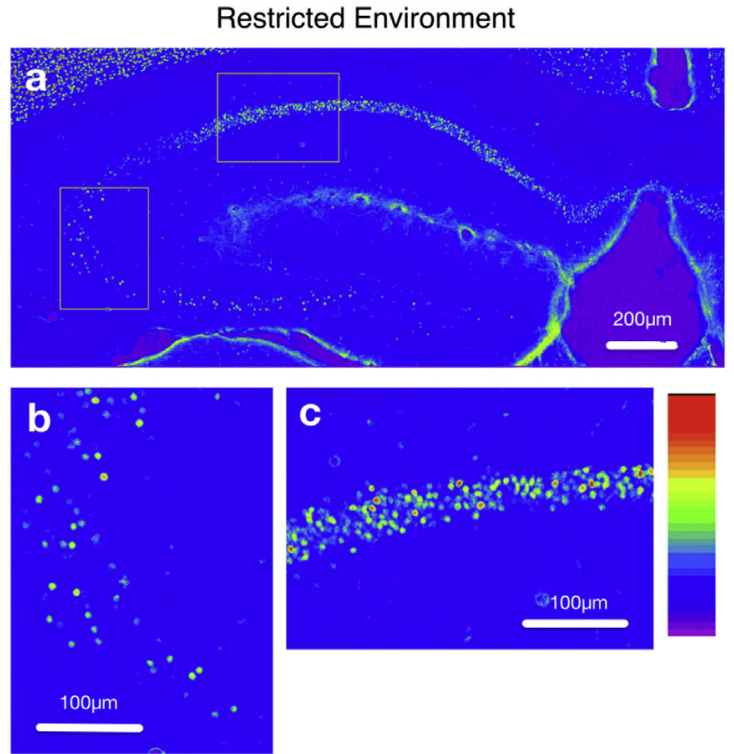

Free Exploration
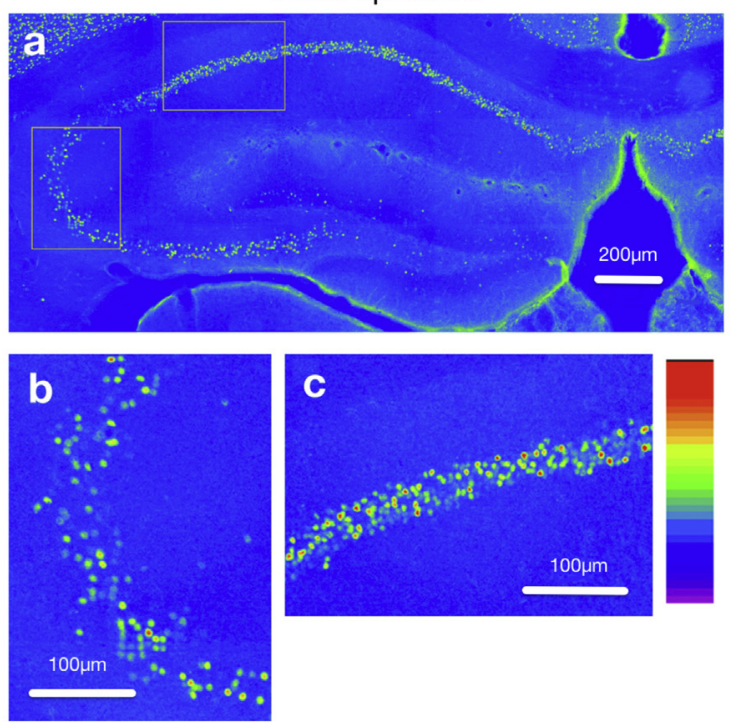

number of active cells could not be completely accounted for by the increase in motor activity, since we did not observe a similar number of Zif268 expressing cells in animals active in a running wheel. However, besides the increases in movement (during exploration of the entire
Fig. 4. Effects of $N M D A_{R}$ antagonism on Zif268 IR cell distribution. (A) 8-arm maze, used to test mice. The maze was located in a black painted room with visual cues placed either on the wall (top) or on the maze arm itself (lower left). The maze arms were enclosed with clear plexiglas. In the center of the maze, animals were kept within a stainless steel cylinder which was covered with a plexiglass. (B) Representative Zif268 expression images. Lower case letters show: a, entire hippocampus; $\mathrm{b}$ and $\mathrm{c}$, magnification of area indicated with square box in CA3 and CA1, respectively. In the Fixed-Location group (top, $\mathrm{n}=4)$, administration of the $\mathrm{NMDA}_{\mathrm{R}}$ antagonist CPP $(10 \mathrm{mg} / \mathrm{kg}$, IP), prior to exposure to the maze (single arm in the 8-arm radial maze), produced a significant, suppression as measured by both the average number of cell clusters $(\mathrm{p}<0.02)$ and the distance between clusters $(\mathrm{p}<0.04)$, in comparison to vehicle treated animals $(n=4)$. CPP administration also markedly suppressed the number of Zif268 IR cells in the Free-Exploration group (bottom, n = 4; all arms in the 8-arm radial maze), in comparison to non-treated animals (see, Fig. 1).

maze), the animal may have experienced other sensory inputs (e.g., olfactory, somatosensory) which could also account for the increased Zif268 expression. This possibility will have to be further investigated.

Using IEGs (e.g., c-fos, Zif268, Arc, Homer1a), previous studies reported a high correlation between IEG expressing cells and spatial exploration/learning (Chawla et al., 2005; Guzowski et al., 1999, 2001; Vazdarjanova et al., 2006). The basic behavioral paradigm has been to let animals either freely explore or to manually move them throughout all parts of a small environment (e.g., square box, linear track), following which they were euthanized and IEG expression determined. The results from these experiments show that approximately $40 \%$ of hippocampal pyramidal cells in the CA1 and CA3 regions express Arc, Homer 1a and Zif268, similar to what we observed in the Free-Exploration group. None of these studies reported a topographical organization in IEG expression based on spatial location or the animal's behavior. On the contrary, a study by Redish et al. (2001) in which a systematic analysis of combined IEG expression and unit recordings were performed, it was concluded that "there is virtually no anatomical clustering of spatial or temporal firing characteristics among dorsal hippocampal CA1 pyramidal cells". A major difference between the present and previous studies is the fact that we deliberately restricted our animals to a small part of the environment, while in previous studies the animals explored the entire space.

One possible explanation for the discrepancy between the clustertype organization that we have identified and the non-topographic organization suggested by electrophysiological studies could be the limited number of units that can be simultaneously recorded; further confounded by the tight arrangement of cells in the CA1/CA3 fields. As can be seen in Fig. 1A, although the cells within the clusters are in close proximity, they are not necessarily immediate neighbors. This could possibly reflect the limited cue environment the animals were exposed to, the limited time of the exposure, etc. Another plausible explanation could be the use of tetrodes for recordings in previous studies; granted, these are relatively small (usually less than $100 \mu \mathrm{m}$ in diameter), they could still be significantly large, which combined with the jagged edges from the twisted bundle, can cause sufficient deformation of the brain tissue and disrupt the identified clusters. Thus, cells recorded with tetrodes may not in reality be neighbors and may come from outside the clusters. On the other hand, with the sharp electrodes and their high impedance used in the present experiment, we could usually record from one cell with clear place fields, even though the electrode was located in the vicinity of a cluster of Zif268 cells. The behavioral characteristics of cells within a cluster and possible correlations of cells across clusters will have to be investigated in future studies.

It should also be noted that although it is generally thought that no functional neuronal organization exists, several electrophysiological studies have reported a topographic organization of hippocampal neurons in rats performing a spatial task (Eichenbaum et al., 1989; Hampson et al., 1999), or spatial exploration (Hirase, Leinekugel, 
Table 2

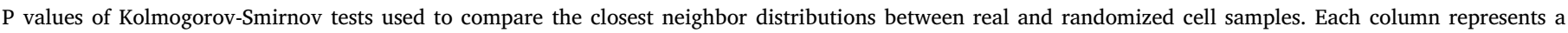
different animal.

\begin{tabular}{|c|c|c|c|c|c|c|c|c|}
\hline \multirow{2}{*}{$\begin{array}{l}\text { Hipp. Field } \\
\text { CA1 }\end{array}$} & \multicolumn{4}{|c|}{ Fixed-Location } & \multicolumn{4}{|c|}{ CPP-Injected } \\
\hline & 0.0004 & 0.0012 & 0.0004 & 0.1020 & 0.0002 & 0.2361 & 0.1309 & 0.0300 \\
\hline CA3 & 0.0044 & 0.250 & 0.0340 & 0.0450 & 0.1020 & 0.2387 & 0.0048 & 0.1117 \\
\hline
\end{tabular}

Csicsvari, Czurko, \& Buzsaki, 2001). However, these results were based on simultaneous multi-unit recordings from tetrodes that did not allow the assessment of the physical localization of active cells. Using twophoton calcium imaging of hippocampal neurons in mice presented a virtual reality environment, a significant cross correlation in unit activity was observed among identified neighboring $(<35 \mu \mathrm{m})$ cells but not for more distant cells (Dombeck, Harvey, Tian, Looger, \& Tank, 2010). Similarly, using calcium imaging to detect neuronal activation, a clustering of cells was reported in the CA3 field, in vitro (Li, Ouyang, Usami, Ikegaya, \& Sik, 2010). Our findings of a cluster-type organization of hippocampal pyramidal cells are in agreement with these studies.

Cells with distinct place fields are mainly seen in the dorsal CA1/ CA3 hippocampal fields (Muller, 1996; O'Keefe, 1976), while in the ventral hippocampus there are considerably fewer place cells and their spatial selectivity is lower (Jung, Wiener, \& McNaughton, 1994), or their spatial scale is greatly increased (Kjelstrup et al., 2008; although see, Poucet, Thinus-Blanc, \& Muller, 1994). Consistent with this, we observed relatively fewer Zif268 IR cells in the ventral hippocampus and there was no evidence of clustering (Fig. 3). Similarly, we observed very few Zif268 expressing cells in the DG. Sparse expression of Arc mRNA in the DG was also reported in animals following a spatial experience (Chawla et al., 2005). DG granule cells have been reported to have place cell characteristics, however, their firing rates are very low and their place fields tend to be smaller and discontinuous (Jung \& McNaughton, 1993; Leutgeb, Leutgeb, Moser, \& Moser, 2007). Thus, the low firing rates and reduced chances of granule cells having a place field within a particular environment could account for the low number of Zif268 expressing cells in the DG. A small number of excitable DG granule cells in animals exposed to different environments has been reported previously (Alme et al., 2010). (It should be noted that DG granule cells do express Zif268 at very high levels, under various stimulation conditions (Abraham, Christie, Logan, Lawlor, \& Dragunow, 1994; French et al., 2001; Richardson et al., 1992; Worley et al., 1993). Thus, the low number of active cells in the present study is not due to a lack of Zif268 expression in this field.)

$\mathrm{N}$-methyl-D-aspartate receptors $\left(\mathrm{NMDA}_{\mathrm{R}}\right)$ play a major role in spatial learning/memory (Davis, Butcher, \& Morris, 1992; Morris, 1989; Morris, Anderson, Lynch, \& Baudry, 1986). Place cell firing also depends on $\mathrm{NMDA}_{\mathrm{R}}$ - both genetic and pharmacological manipulations of $\mathrm{NMDA}_{\mathrm{R}}$ disrupt place cell activity. Specifically, in $\mathrm{NMDA}_{\mathrm{R} 1, \mathrm{R} 2}$ knockout mice there is a disintegration of place fields, as revealed by the lower number of encountered place cells and their reduced precision of place fields (McHugh, Blum, Tsien, Tonegawa, \& Wilson, 1996; Tonegawa et al., 1996; Yan et al., 2002). Similarly, intra-hippocampal administration of the $\mathrm{NMDA}_{R}$ antagonist CPP (3-(2-carboxypiperazin-4-yl)propyl-1-phosphonic acid) disrupts spatial selectivity (Ekstrom, Meltzer, McNaughton, \& Barnes, 2001), while a systemic administration of CPP (Kentros et al., 1998) or the specific mGlu5 receptor inhibitor MPEP (2-methyl-6-(phenylethynyl) pyridine; (Zhang \& Manahan-Vaughan, 2014) disrupts the long-term stability of place fields. The present results confirm these previous findings - blockade of $\mathrm{NMDA}_{\mathrm{R}}$ significantly suppressed the number of Zif268 IR cells (both in the Fixed Location and Free Exploration groups), although it did not eliminate them.

The present study suggests that the Zif268 IR clusters constitute a basic unit of topographically arranged hippocampal neurons to encode for space. A number of questions arise from these results: (1) what is the global organization of the clusters within the hippocampus? This could be answered by using similar behavioral/neuroanatomical methods to the present study and performing a 3-D reconstruction of the entire structure (as well as other cortical (e.g., entorhinal cortex (Fyhn et al., 2004; Hargreaves, Rao, Lee, \& Knierim, 2005) and subcortical areas (e.g., subiculum (Barnes, McNaughton, Mizumori, Leonard, \& Lin, 1990); parasubiculum (Taube, 1995, in which cells with spatial tuning have been identified); (2) how do cells within a cluster, as well as between clusters, process spatial information? As stated above, the majority of studies thus far have reported no correlation between neighboring cells and their place fields. However, with the ability to identify cells belonging to the same cluster and to perform cross correlation analysis between their activity, as well as the activity across clusters, a better picture could emerge of the spatial map; (3) is the neuronal organization comprising the spatial map hard-wired or is it plastic and constantly evolving with each new environment? In other words, do the same cells participate in limited or multiple maps? It is well known that place cells have stable place fields over long periods of time (months, Thompson \& Best, 1990); however, they can also have multiple place fields within one environment or fields in different environments. Using nuclear and cytoplasmic co-localization after sequential double stimulation (i.e., catFISH expression analysis of arc or Zif268), it has been reported (Guzowski et al., 1999) that the majority ( $\sim 90 \%$ ) of hippocampal pyramidal cells are double labelled in animals exposed to the same environment twice, in comparison to animals that are exposed to two different environments, for which considerably fewer cells $(\sim 20 \%)$ were double labeled. In a separate study (Nakamura et al., 2010), we confirmed this finding (although the percentage of double labelled units was lower, perhaps due to the restricted environment used) and further showed that in the same environment exposed animals, not only are there twice as many double labelled cells but they also form more compactly arranged clusters. Still, although the clusters may form the basic building blocks for the spatial map, interactions between cells within a cluster and across clusters may be as significant in dealing with the unlimited environments an organism may encounter; (4) finally, although we have observed a physical topographic organization of hippocampal neurons (i.e, clusters), it is possible that this organization is dynamically modulated as evidenced by remapping of place fields (Muller \& Kubie, 1987; for review, see Colgin, Moser, \& Moser, 2008). Nonetheless, knowing that a topographic organization exists could greatly enhance decoding of the spatial map.

\section{Data accessibility}

Data are available upon request.

\section{Acknowledgements}

This work was supported by NIH grants 5R01MH67283 and USJapan BRCP grant to CP. The authors like to thank Alice WarrenGregory, Yvgenia Gyrda, Maria de los Reyes, Kimberly Resnick, Emily Gotschlich, Kelsey Lafer and Jason Mogen for help with behavioral testing, IHC and anatomical analysis. The authors are also indebted to Sarah Maguire for her technical support and Dr. Eric L. Hargreaves for assistance with unit analysis. 
A
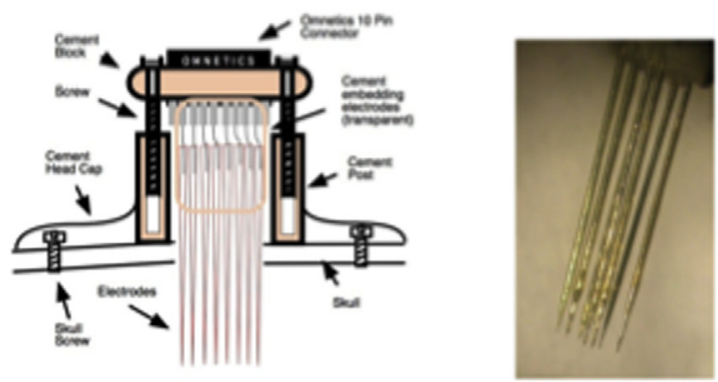

C

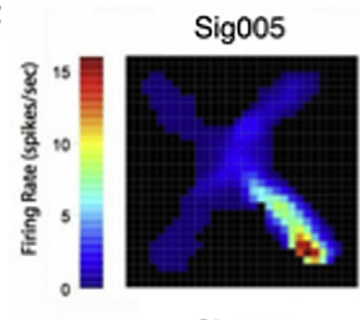

Sig007

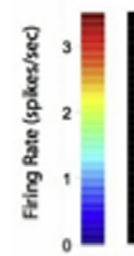

$\mathbf{E}$

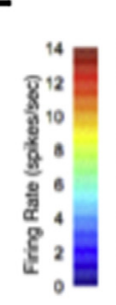

Sig003
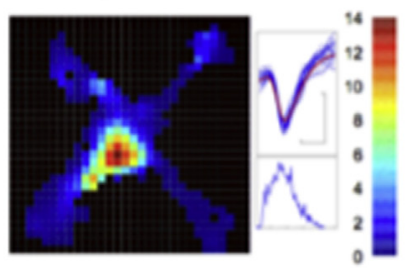

Sig005

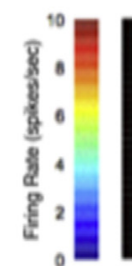

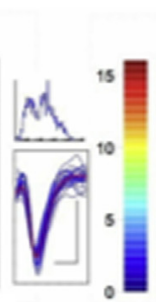

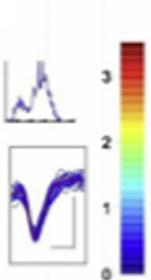

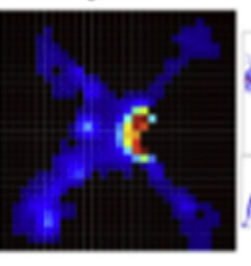

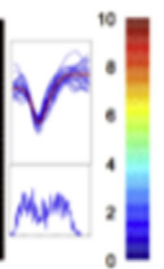

Sig005

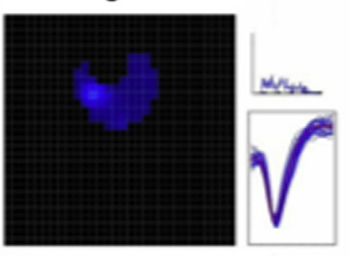

Sig007

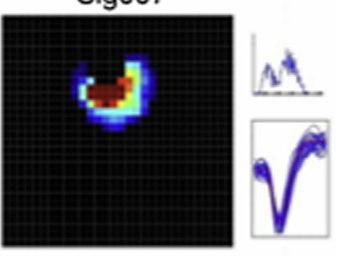

Sig003

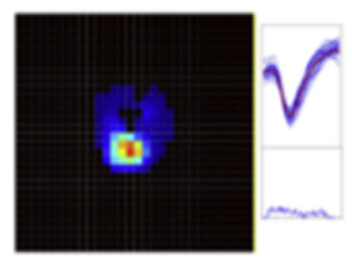

Sig005

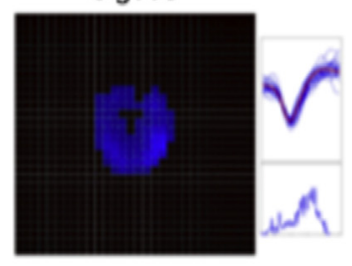

B

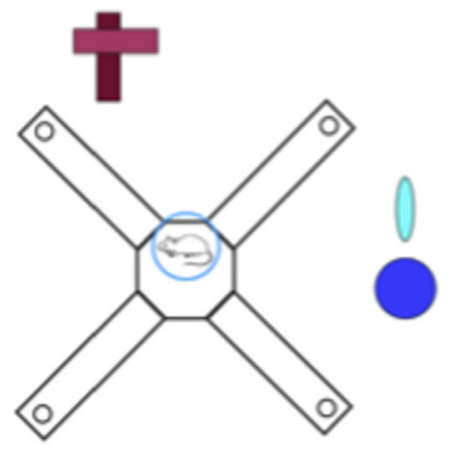

D

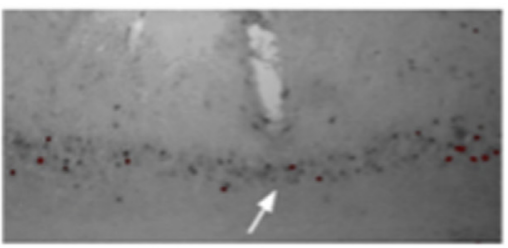

$\mathbf{F}$

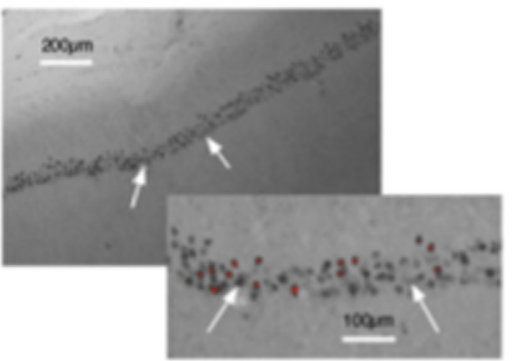

Fig. 5. Multi-array recordings within Zif268 IR cell clusters. (A) Schematic of microdrive and multi-electrode array. (B) Schematic of plus maze. The maze was located in a black painted room, approximately $3 \mathrm{~m}^{2}$. Distinct visual cues were placed on the walls. (C) Place cell recordings performed in the CA3 hippocampal field. Recordings were made from two different electrodes (Cell 1 (sig005) and Cell 2 (sig007)). During initial mapping of place fields (left panels), Cell 1 (top) had a place field extending the length of the lower right arm, while Cell 2 (bottom) had two disjointed but distinct place fields on the upper left arm (close to the center of the maze) and on the lower right arm. On the day of the experiment, the animal was exposed to the place field of Cell 2, on the border of the upper left arm/center of maze (right lower panel), while keeping it away from the place field of Cell 1. During exposure there was significant firing of Cell 2, but not Cell 1. The inter-spike interval histograms (ISIH) are in common log scales, range 1-100,000 ms. Ordinate on all panels is in the range of 0-60. Waveform calibrations: $150 \mu \mathrm{V}, 0.25 \mathrm{~ms}$. (D) Histological sections showing Zif268 IR cells (red) along with electrode placement. The electrode tip for Cell 1 (upper) was located in a non-cluster (arrow) while the tip for Cell 2 (lower) was localized within a Zif268 IR cluster (arrow). The electrode track, above the cell body layer was made by the shaft of the electrode, which was larger than the sharp tip. (E) Place cell recordings performed in the CA1 hippocampal field. Recordings were made from two different electrodes (Cell 1 (sig003) and Cell 2 (sig005)). During initial mapping of place fields (left panels), Cell 1 (top) had a place field on the lower right arm, close to the center while Cell 2 (bottom) had a place field on right center. On the day of the experiment, the animal was exposed to the place field of Cell 2 on the border of the upper left arm/center of maze (right lower panel), while being kept away from the place field of Cell 1. During exposure there was significant firing of Cell 2, but not Cell 1. (F) Histological sections showing Zif268 IR cells (red) along with electrode placement. The electrode tip for Cell 1 (upper) was located in a non-cluster (arrow) while the tip for Cell 2 (lower) was localized within a Zif268 IR cluster (arrow). (For interpretation of the references to color in this figure legend, the reader is referred to the web version of this article.) 
A

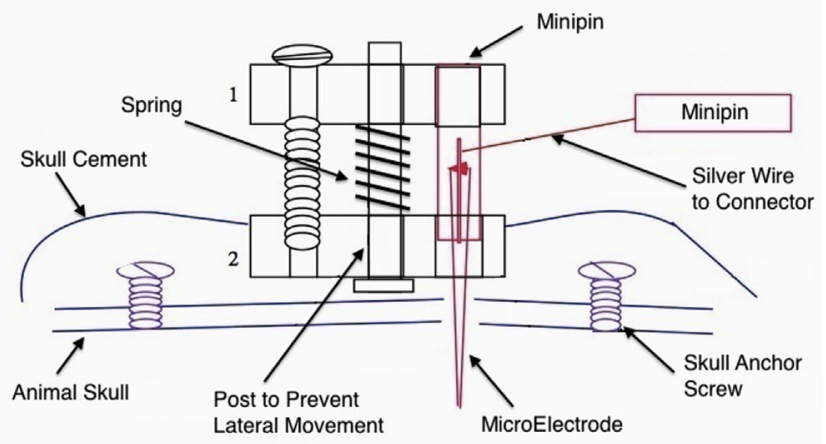

B

\section{Spike waveform}
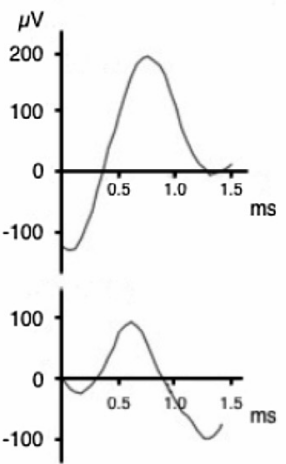

Firing rate
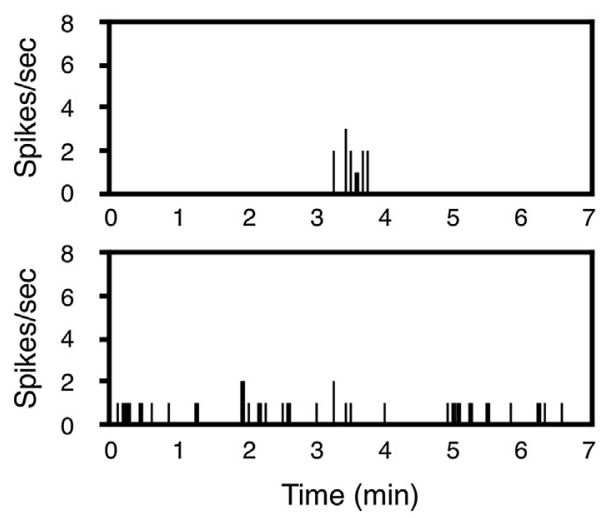

C

\section{Place field}
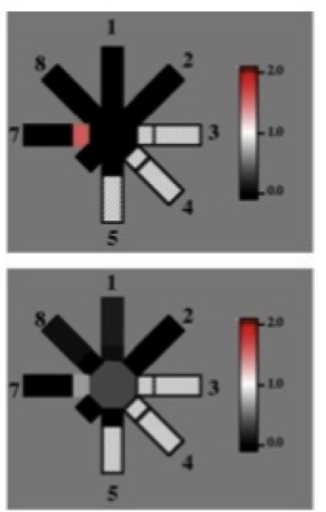

D
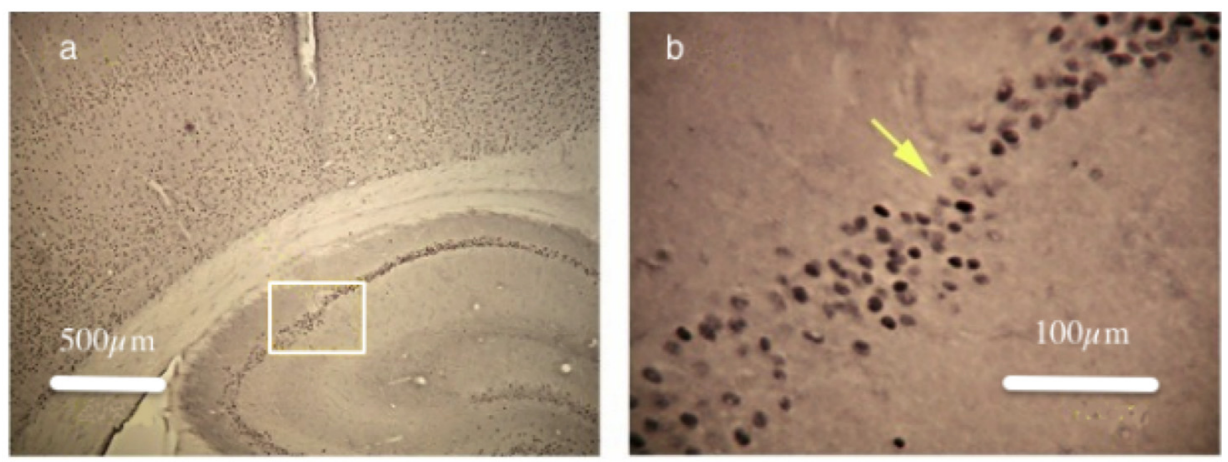

$\mathbf{E}$
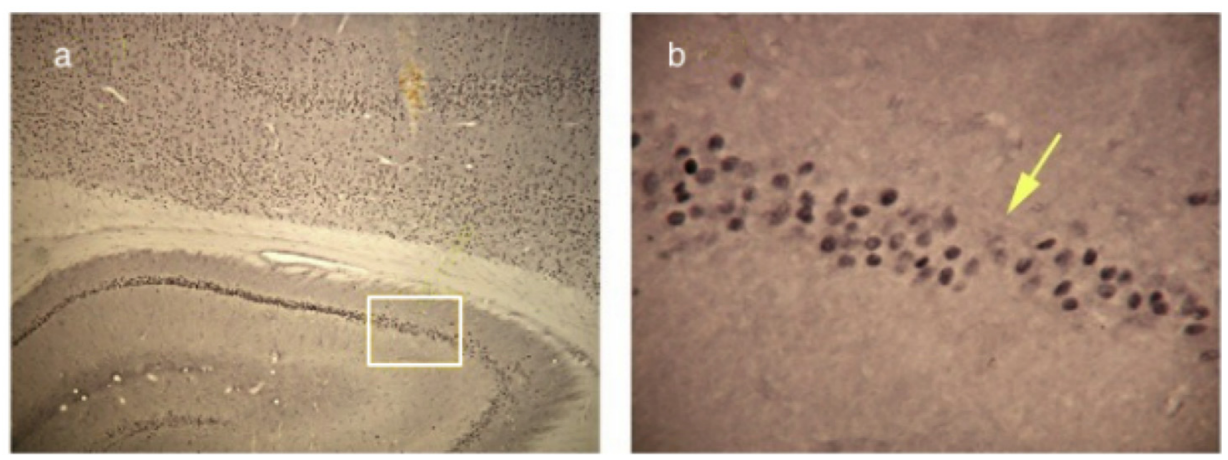

Fig. 6. Single sharp electrode recordings within Zif268 clusters from two hemispheres. (A) Schematic of microdrive and electrode assembly. (B) Recordings showing representative spike waveforms (left panel) along with firing rate histograms (middle panel), and place field rate distribution maps (C), for two simultaneously recorded cells. Cell 1 (top) had a circumscribed place field at the start of arm 7/center platform, while Cell 2 (bottom) showed enhanced firing on arms 3-5. During exposure, the animal was confined to Cell 1's place field. (D) Distribution of Zif268 IR cells in the CA1 hippocampal field, along with recording electrode tracts, in the two hemispheres. The placement of the electrode in the left hemisphere (Cell 1) was within one of the Zif268 IR clusters, as shown in (a) (a', area indicated with square in a), while the electrode in the right hippocampus (Cell 2) was located outside the active Zif268 IR clusters as shown in b (b', area indicated with square in b). Arrows point to area just above electrode tips. Note that the electrodes caused minimum damage, which allowed recordings within individual cell clusters.

\section{Conflict of interest}

The authors declare no financial, personal or other conflicts of interest.

\section{Author contributions}

C.P. oversaw each part of the experimental design, data collection and analysis and manuscript preparation. T.D. performed part of the unit recording studies, along with IHC. S.R, and C.V.M. performed some 
of the IHC and were involved in experimental design and interpretation of data. W.B. performed the clustering simulation analysis. S.O. performed the majority of IHC and was involved in experimental design, data collection, analysis and interpretation of data. All the authors discussed the results and commented on the manuscript.

\section{References}

Abraham, W. C., Christie, B. R., Logan, B., Lawlor, P., \& Dragunow, M. (1994). Immediate early gene expression associated with the persistence of heterosynaptic long-term depression in the hippocampus. Proceedings of the National Academy of Sciences of the United States of America, 91(21), 10049-10053.

Alme, C. B., Buzzetti, R. A., Marrone, D. F., Leutgeb, J. K., Chawla, M. K., Schaner, M. J., et al. (2010). Hippocampal granule cells opt for early retirement. Hippocampus, 20(10), 1109-1123. https://doi.org/10.1002/hipo.20810.

Andersen, P., Bliss, T. V., \& Skrede, K. K. (1971). Lamellar organization of hippocampal pathways. Experimental Brain Research, 13(2), 222-238.

Barnes, C. A., McNaughton, B. L., Mizumori, S. J., Leonard, B. W., \& Lin, L. H. (1990). Comparison of spatial and temporal characteristics of neuronal activity in sequential stages of hippocampal processing. Progress in Brain Research, 83, 287-300.

Buzsáki, G. (2010). Neural syntax: Cell assemblies, synapsembles, and readers. Neuron, 68(3), 362-385. https://doi.org/10.1016/j.neuron.2010.09.023.

Chawla, M. K., Guzowski, J. F., Ramirez-Amaya, V., Lipa, P., Hoffman, K. L., Marriott, L. K., et al. (2005). Sparse, environmentally selective expression of Arc RNA in the upper blade of the rodent fascia dentata by brief spatial experience. Hippocampus, 15(5), 579-586. https://doi.org/10.1002/hipo.20091.

Colgin, L. L., Moser, E. I., \& Moser, M.-B. (2008). Understanding memory through hippocampal remapping. Trends in Neurosciences, 31(9), 469-477. https://doi.org/10. 1016/j.tins.2008.06.008.

Dabaghian, Y., Mémoli, F., Frank, L., \& Carlsson, G. (2012). A topological paradigm for hippocampal spatial map formation using persistent homology. PLoS Computational Biology, 8(8), e1002581. https://doi.org/10.1371/journal.pcbi.1002581.

Davis, S., Butcher, S., \& Morris, R. (1992). The NMDA receptor antagonist D-2-amino-5phosphonopentanoate (D-AP5) impairs spatial learning and LTP in vivo at intracerebral concentrations comparable to those that block LTP in vitro. The Journal of Neuroscience: the Official Journal of the Society for Neuroscience, 12(1), 21-34.

Deadwyler, S. A., \& Hampson, R. E. (1999). Anatomic model of hippocampal encoding of spatial information. Hippocampus, 9(4), 397-412. https://doi.org/10.1002/(SICI) 1098-1063(1999) 9:4<397::AID-HIPO6 > 3.0.CO;2-C.

Dombeck, D. A., Harvey, C. D., Tian, L., Looger, L. L., \& Tank, D. W. (2010). Functional imaging of hippocampal place cells at cellular resolution during virtual navigation. Nature Neuroscience, 13(11), 1433-1440. https://doi.org/10.1038/nn.2648.

Eichenbaum, H., Dudchenko, P., Wood, E., Shapiro, M., \& Tanila, H. (1999). The hippocampus, memory, and place cells: Is it spatial memory or a memory space? Neuron, 23(2), 209-226.

Eichenbaum, H., Wiener, S. I., Shapiro, M. L., \& Cohen, N. J. (1989). The organization of spatial coding in the hippocampus: A study of neural ensemble activity. The Journal of Neuroscience: the Official Journal of the Society for Neuroscience, 9(8), 2764-2775.

Ekstrom, A. D., Meltzer, J., McNaughton, B. L., \& Barnes, C. A. (2001). NMDA receptor antagonism blocks experience-dependent expansion of hippocampal "place fields". Neuron, 31(4), 631-638.

Frank, L. M., Stanley, G. B., \& Brown, E. N. (2004). Hippocampal plasticity across multiple days of exposure to novel environments. Journal of Neuroscience, 24(35), 7681-7689. https://doi.org/10.1523/JNEUROSCI.1958-04.2004.

French, P. J., O'Connor, V., Jones, M. W., Davis, S., Errington, M. L., Voss, K., et al. (2001). Subfield-specific immediate early gene expression associated with hippocampal long-term potentiation in vivo. The European Journal of Neuroscience, 13(5), 968-976.

Fyhn, M., Fyhn, M., Molden, S., Molden, S., Witter, M. P., Witter, M. P., et al. (2004). Spatial representation in the entorhinal cortex. Science, 305(5688), 1258-1264. https://doi.org/10.1126/science.1099901.

Guzowski, J. F., McNaughton, B. L., Barnes, C. A., \& Worley, P. F. (1999). Environmentspecific expression of the immediate-early gene Arc in hippocampal neuronal ensembles. Nature Neuroscience, 2(12), 1120-1124. https://doi.org/10.1038/16046.

Guzowski, J. F., Setlow, B., Wagner, E. K., \& McGaugh, J. L. (2001). Experience-dependent gene expression in the rat hippocampus after spatial learning: A comparison of the immediate-early genes Arc, c-fos, and zif268. The Journal of Neuroscience: the Official Journal of the Society for Neuroscience, 21(14), 5089-5098.

Guzowski, J. F., Timlin, J. A., Roysam, B., McNaughton, B. L., Worley, P. F., \& Barnes, C. A. (2005). Mapping behaviorally relevant neural circuits with immediate-early gene expression. Current Opinion in Neurobiology, 15(5), 599-606. https://doi.org/10. 1016/j.conb.2005.08.018.

Hampson, R. E., Byrd, D. R., Konstantopoulos, J. K., Bunn, T., \& Deadwyler, S. A. (1996). Hippocampal place fields: Relationship between degree of field overlap and crosscorrelations within ensembles of hippocampal neurons. Hippocampus, 6(3), 281-293. https://doi.org/10.1002/(SICI)1098-1063(1996) 6:3<281::AID-HIPO6 > 3.0. CO;2-Q.

Hampson, R. E., Simeral, J. D., \& Deadwyler, S. A. (1999). Distribution of spatial and nonspatial information in dorsal hippocampus. Nature, 402(6762), 610-614. https:// doi.org/10.1038/45154.

Hargreaves, E. L., Rao, G., Lee, I., \& Knierim, J. J. (2005). Major dissociation between medial and lateral entorhinal input to dorsal hippocampus. Science, 308(5729), 1792-1794. https://doi.org/10.1126/science.1110449.
Harris, K. D. (2005). Neural signatures of cell assembly organization. Nature Reviews Neuroscience, 6(5), 399-407. https://doi.org/10.1038/nrn1669.

Harris, K. D., Csicsvari, J., Hirase, H., Dragoi, G., \& Buzsáki, G. (2003). Organization of cell assemblies in the hippocampus. Nature, 424(6948), 552-556. https://doi.org/10. 1038/nature01834.

Hill, A. (1978). First occurrence of hippocampal spatial firing in a new environment. Experimental Neurology, 62, 282-297.

Hirase, H., Leinekugel, X., Csicsvari, J., Czurko, A., \& Buzsaki, G. (2001). Behavior-dependent states of the hippocampal network affect functional clustering of neurons. The Journal of Neuroscience: the Official Journal of the Society for Neuroscience, 21(10), RC145.

Hubel, D., \& Wiesel, T. (1965). Receptive fields and functional architecture in two nonstriate visual areas (18 and 19) of the cat. Journal of Neurophysiology, 28, 229-289.

Jung, M. W., \& McNaughton, B. L. (1993). Spatial selectivity of unit activity in the hippocampal granular layer. Hippocampus, 3(2), 165-182. https://doi.org/10.1002/ hipo.450030209.

Jung, M. W., Wiener, S. I., \& McNaughton, B. L. (1994). Comparison of spatial firing characteristics of units in dorsal and ventral hippocampus of the rat. The Journal of Neuroscience: the Official Journal of the Society for Neuroscience, 14(12), 7347-7356.

Kawashima, T., Okuno, H., \& Bito, H. (2014). A new era for functional labeling of neurons: Activity-dependent promoters have come of age. Front Neural Circuits, 8, 37. https://doi.org/10.3389/fncir.2014.00037.

Kentros, C., Hargreaves, E., Hawkins, R. D., Kandel, E. R., Shapiro, M., \& Muller, R. V. (1998). Abolition of long-term stability of new hippocampal place cell maps by NMDA receptor blockade. Science, 280(5372), 2121-2126.

Kjelstrup, K. B., Solstad, T., Brun, V. H., Hafting, T., Leutgeb, S., Witter, M. P., et al. (2008). Finite scale of spatial representation in the hippocampus. Science, 321(5885), 140-143. https://doi.org/10.1126/science.1157086.

Kubik, S., Miyashita, T., \& Guzowski, J. F. (2007). Using immediate-early genes to map hippocampal subregional functions. Learning \& Memory (Cold Spring Harbor, NY), 14(11), 758-770. https://doi.org/10.1101//m.698107.

Leutgeb, J. K., Leutgeb, S., Moser, M.-B., \& Moser, E. I. (2007). Pattern separation in the dentate gyrus and CA3 of the hippocampus. Science, 315(5814), 961-966. https:// doi.org/10.1126/science.1135801.

Li, X., Ouyang, G., Usami, A., Ikegaya, Y., \& Sik, A. (2010). Scale-free topology of the CA3 hippocampal network: A novel method to analyze functional neuronal assemblies. Biophysical Journal, 98(9), 1733-1741. https://doi.org/10.1016/j.bpj.2010.01.013.

Maguire, E. A., Burgess, N., Donnett, J. G., Frackowiak, R. S., Frith, C. D., \& O'Keefe, J. (1998). Knowing where and getting there: A human navigation network. Science, 280(5365), 921-924.

McHugh, T. J., Blum, K. I., Tsien, J. Z., Tonegawa, S., \& Wilson, M. A. (1996). Impaired hippocampal representation of space in CA1-specific NMDAR1 knockout mice. Cell, 87(7), 1339-1349.

McNaughton, B., \& Morris, R. (1987). Hippocampal synaptic enhancement and information storage within a distributed memory system. Tins, 10(10), 408-415.

Mello, C. V., \& Ribeiro, S. (1998). ZENK protein regulation by song in the brain of songbirds. The Journal of Comparative Neurology, 393(4), 426-438.

Miyashita, T., Kubik, S., Lewandowski, G., \& Guzowski, J. F. (2008). Networks of neurons, networks of genes: An integrated view of memory consolidation. Neurobiology of Learning and Memory, 89(3), 269-284. https://doi.org/10.1016/j.nlm.2007.08.012.

Morris, R. G. (1989). Synaptic plasticity and learning: Selective impairment of learning rats and blockade of long-term potentiation in vivo by the N-methyl-D-aspartate receptor antagonist AP5. The Journal of Neuroscience the Official Journal of the Society for Neuroscience, 9(9), 3040-3057.

Morris, R., Anderson, E., Lynch, G., \& Baudry, M. (1986). Selective impairment of learning and blockade of long-term potentiation by an N-methyl-D-aspartate receptor antagonist, AP5. Nature, 319, 774-776.

Mountcastle, V. B. (1997). The columnar organization of the neocortex. Brain, 120(Pt 4), $701-722$.

Muller, R. (1996). A quarter of a century of place cells. Neuron, 17(5), 813-822.

Muller, R. U., \& Kubie, J. L. (1987). The effects of changes in the environment on the spatial firing of hippocampal complex-spike cells. The Journal of Neuroscience: the Official Journal of the Society for Neuroscience, 7(7), 1951-1968.

Muller, R. U., Kubie, J. L., \& Ranck, J. B. (1987). Spatial firing patterns of hippocampal complex-spike cells in a fixed environment. The Journal of Neuroscience: the Official Journal of the Society for Neuroscience, 7(7), 1935-1950.

Nakamura, N. H., Fukunaga, M., Akama, K. T., Soga, T., Ogawa, S., \& Pavlides, C. (2010). Hippocampal cells encode places by forming small anatomical clusters. Neuroscience, 166(3), 994-1007. https://doi.org/10.1016/j.neuroscience.2009.12.069.

Nakazawa, K., McHugh, T. J., Wilson, M. A., \& Tonegawa, S. (2004). NMDA receptors, place cells and hippocampal spatial memory. Nature Reviews Neuroscience, 5(5), 361-372. https://doi.org/10.1038/nrn1385.

O'Keefe, J., Burgess, N., Donnett, J. G., Jeffery, K. J., \& Maguire, E. A. (1998). Place cells, navigational accuracy, and the human hippocampus. Philosophical Transactions of the Royal Society of London. Series B: Biological Sciences, 353(1373), 1333-1340. https:// doi.org/10.1098/rstb.1998.0287.

O'Keefe (1976). Place units in the hippocampus of the freely moving rat. Experimental Neurology, 51, 78-109.

O'Keefe, J., \& Dostrovsky, J. (1971). The hippocampus as a spatial map. Preliminary evidence from uni activity in freely-moving rat. Brain Research, 34, 171-175.

O'Keefe, J., \& Nadel, L. (1978). The hippocampus as a cognitive map. Oxford: Oxford University Press.

Pastalkova, E., Itskov, V., Amarasingham, A., \& Buzsáki, G. (2008). Internally generated cell assembly sequences in the rat hippocampus. Science, 321(5894), 1322-1327. https://doi.org/10.1126/science.1159775.

Poucet, B., Save, E., \& Lenck-Santini, P. P. (2000). Sensory and memory properties of 
hippocampal place cells. Nature Reviews Neuroscience, 11(2-3), 95-111.

Poucet, B., Thinus-Blanc, C., \& Muller, R. U. (1994). Place cells in the ventral hippocampus of rats. NeuroReport, 5(16), 2045-2048.

Redish, A. D., Battaglia, F. P., Chawla, M. K., Ekstrom, A. D., Gerrard, J. L., Lipa, P., et al. (2001). Independence of firing correlates of anatomically proximate hippocampal pyramidal cells. The Journal of Neuroscience: the Official Journal of the Society for Neuroscience, 21(5), RC134.

Richardson, C. L., Tate, W. P., Mason, S. E., Lawlor, P. A., Dragunow, M., \& Abraham, W. C. (1992). Correlation between the induction of an immediate early gene, zif/268, and long-term potentiation in the dentate gyrus. Brain Research, 580(1-2), 147-154.

Sloviter, R. S., \& Lømo, T. (2012). Updating the lamellar hypothesis of hippocampal organization. Front Neural Circuits, 6, 102. https://doi.org/10.3389/fncir.2012.00102.

Takahata, T., Higo, N., Kaas, J. H., \& Yamamori, T. (2009). Expression of immediate-early genes reveals functional compartments within ocular dominance columns after brief monocular inactivation. Proceedings of the National Academy of Sciences of the United States of America, 106(29), 12151-12155. https://doi.org/10.1073/pnas. 0905092106.

Taube, J. S. (1995). Place cells recorded in the parasubiculum of freely moving rats. Hippocampus, 5(6), 569-583. https://doi.org/10.1002/hipo.450050608.

Thompson, L. T., \& Best, P. J. (1990). Long-term stability of the place-field activity of single units recorded from the dorsal hippocampus of freely behaving rats. Brain Research, 509(2), 299-308.

Tonegawa, S., Tsien, J. Z., McHugh, T. J., Huerta, P., Blum, K. I., \& Wilson, M. A. (1996). Hippocampal CA1-region-restricted knockout of NMDAR1 gene disrupts synaptic plasticity, place fields, and spatial learning. Cold Spring Harbor Symposia on Quantitative Biology, 61, 225-238.

Tsodyks, M. (1999). Attractor neural network models of spatial maps in hippocampus Hippocampus, 9(4), 481-489. https://doi.org/10.1002/(SICI)1098-1063(1999) 9:4<481::AID-HIPO14>3.0.CO;2-S.

Vann, S. D., Brown, M. W., Erichsen, J. T., \& Aggleton, J. P. (2000). Fos imaging reveals differential patterns of hippocampal and parahippocampal subfield activation in rats in response to different spatial memory tests. Journal of Neuroscience, 20(7), 2711-2718.

Vazdarjanova, A., McNaughton, B. L., Barnes, C. A., Worley, P. F., \& Guzowski, J. F. (2002). Experience-dependent coincident expression of the effector immediate-early genes arc and Homer 1a in hippocampal and neocortical neuronal networks. The Journal of Neuroscience: the Official Journal of the Society for Neuroscience, 22(23), 10067-10071.

Vazdarjanova, A., Ramirez-Amaya, V., Insel, N., Plummer, T. K., Rosi, S., Chowdhury, S., et al. (2006). Spatial exploration induces ARC, a plasticity-related immediate-early gene, only in calcium/calmodulin-dependent protein kinase II-positive principal excitatory and inhibitory neurons of the rat forebrain. The Journal of Comparative Neurology, 498(3), 317-329. https://doi.org/10.1002/cne.21003.

Wills, T. J., Lever, C., Cacucci, F., Burgess, N., \& O'Keefe, J. (2005). Attractor dynamics in the hippocampal representation of the local environment. Science, 308(5723), 873-876. https://doi.org/10.1126/science.1108905.

Wilson, M. A., \& McNaughton, B. L. (1993). Dynamics of the hippocampal ensemble code for space. Science, 261(5124), 1055-1058.

Worley, P. F., Bhat, R. V., Baraban, J. M., Erickson, C. A., McNaughton, B. L., \& Barnes, C. A. (1993). Thresholds for synaptic activation of transcription factors in hippocampus: Correlation with long-term enhancement. The Journal of Neuroscience: the Official Journal of the Society for Neuroscience, 13(11), 4776-4786.

Worley, P. F., Christy, B. A., Nakabeppu, Y., Bhat, R. V., Cole, A. J., \& Baraban, J. M. (1991). Constitutive expression of zif268 in neocortex is regulated by synaptic activity. Proceedings of the National Academy of Sciences of the United States of America, 88(12), 5106-5110.

Yan, J., Zhang, Y., Jia, Z., Taverna, F. A., McDonald, R. J., Muller, R. U., et al. (2002). Place-cell impairment in glutamate receptor 2 mutant mice. The Journal of Neuroscience: the Official Journal of the Society for Neuroscience, 22(3), RC204.

Zhang, S., \& Manahan-Vaughan, D. (2014). Place field stability requires the metabotropic glutamate receptor, mGlu5. Hippocampus, 24(11), 1330-1340. https://doi.org/10. 1002/hipo.22314. 